\title{
The genomic sequence of Exiguobacterium chiriqhucha str. N139 reveals a species that thrives in cold waters and extreme environmental conditions
}

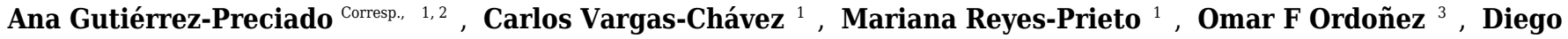 \\ Santos-García ${ }^{1,4}$ ， Tania Rosas-Pérez ${ }^{1}$ ， Jorge Valdivia-Anistro ${ }^{5,6}$, Eria A Rebollar ${ }^{7}$, Andrés Saralegui ${ }^{8}$, \\ Andrés Moya ${ }^{1}$, Enrique Merino ${ }^{9}$, María Eugenia Farías ${ }^{10}$ ， Amparo Latorre ${ }^{\text {Corresp.. }}{ }^{1}$ ， Valeria Souza Corresp. 6 \\ 1 Unidad de Genética Evolutiva, Instituto Cavanilles de Biodiversidad y Biología Evolutiva, Universidad de Valencia, Calle Catedrático José Beltrán \\ Martínez, Paterna, Valencia, Spain \\ 2 Ecologie Systématique Evolution, CNRS, AgroParisTech, Université Paris Sud (Paris XI), Orsay, France \\ 3 Laboratorio de Investigaciones Microbiológicas de Lagunas Andinas, Planta Piloto de Procesos Industriales Microbiológicos (PROIMI), Consejo Nacional de \\ Investigaciones Científicas y Técnicas (CONICET), Av. Belgrano y Pasaje Caseros, San Miguel de Tucumán, Argentina \\ 4 Department of Entomology, Hebrew University of Jerusalem, Rehovot, Israel \\ 5 Carrera de Biología, Faculta de Estudios Superiores Zaragoza, UNAM, Mexico City, Mexico \\ 6 Departamento de Ecología Evolutiva, Instituto de Ecología, Universidad Nacional Autónoma de México, coyoacan, Mexico City, México \\ 7 Department of Biology, James Madison University, Harrisonburg, Virginia, United States of America \\ 8 Laboratorio Nacional de Microscopía Avanzada, Instituto de Biotecnología, Universidad Nacional Autónoma de México, Cuernavaca, Morelos, México \\ 9 Departamento de Microbiología Molecular, Instituto de Biotecnología, Universidad Nacional Autónoma de México, Cuernavaca, Morelos, México \\ 10 Laboratorio de Investigaciones Microbiológicas de Lagunas Andinas, Planta Piloto de Procesos Industriales Microbiológicos (PROIMI), Consejo Nacional \\ de Investigaciones Científicas y Técnicas, Av. Belgrano y Pasaje Caseros, San Miguel de Tucumán, Argentina \\ Corresponding Authors: Ana Gutiérrez-Preciado, Amparo Latorre, Valeria Souza \\ Email address: anagtz@gmail.com, Amparo.Latorre@uv.es, souza.valeria2@gmail.com
}

We report the genome sequence of Exiguobacterium chiriqhucha str. N139, isolated from a high-altitude Andean lake. Comparative genomic analyses of the Exiguobacterium genomes available suggest that our strain belongs to the same species as the previously reported E. pavilionensis str. RW-2 and Exiguobacterium str. GIC 31. We describe this species and propose the chiriqhucha name to group them. 'Chiri qhucha' in quechua means 'cold lake', which is a common origin of these three cosmopolitan Exiguobacteria. The 2,952,588-bp E. chiriqhucha str. N139 genome contains one chromosome and three megaplasmids. The genome analysis of the Andean strain suggests the presence of enzymes that confer $E$. chiriqhucha str. N139 the ability to grow under multiple environmental extreme conditions, including high concentrations of different metals, high ultraviolet B radiation, scavenging for phosphorous and coping with high salinity. Moreover, the regulation of its tryptophan biosynthesis suggests that novel pathways remain to be discovered, and that these pathways might be fundamental in the amino acid metabolism of the microbial community from Laguna Negra, Argentina. 


\title{
The genomic sequence of Exiguobacterium chiriqhucha str. N139 reveals a species that thrives in cold waters and extreme environmental conditions
}

\author{
Ana Gutiérrez-Preciado ${ }^{1 \uparrow}$, Carlos Vargas-Chávez ${ }^{1 \dagger}$, Mariana Reyes-Prieto ${ }^{1}$, Omar F Ordoñez ${ }^{2}$, Diego \\ Santos-Garcia ${ }^{1 \rho}$, Tania Rosas-Pérez ${ }^{1}$, Jorge Valdivia-Anistro $^{3 \pm}$, Eria A Rebollar ${ }^{4}$, Andrés Saralegui ${ }^{5}$, Andrés \\ Moya $^{1}$, Enrique Merino ${ }^{6}$, María Eugenia Farias ${ }^{2}$, Amparo Latorre ${ }^{1 *}$ and Valeria Souza ${ }^{3 *}$.
}

\footnotetext{
${ }^{*}$ Corresponding authors: Amparo Latorre E-mail: amparo.latorre@uv.es; Valeria Souza E-mail: souza@servidor.unam.mx

$\dagger$ Equal contributors
}

${ }^{1}$ Unidad de Genética Evolutiva, Instituto Cavanilles de Biodiversidad y Biología Evolutiva, Universidad de Valencia, Calle

Catedrático José Beltrán Martínez 2, 46980, Paterna, Spain

${ }^{2}$ Laboratorio de Investigaciones Microbiológicas de Lagunas Andinas (LIMLA), Planta Piloto de Procesos Industriales Microbiológicos (PROIMI), Consejo Nacional de Investigaciones Científicas y Técnicas (CONICET), Av. Belgrano y Pasaje Caseros, 4000 San Miguel de Tucumán, Argentina

${ }^{3}$ Departamento de Ecología Evolutiva, Instituto de Ecología, Universidad Nacional Autónoma de México, México D.F., México

${ }^{4}$ Department of Biology, James Madison University, Harrisonburg, Virginia, 22801, United States of America

${ }^{5}$ Laboratorio Nacional de Microscopía Avanzada, Instituto de Biotecnología, Universidad Nacional Autónoma de México, Cuernavaca, Morelos, México

${ }^{6}$ Departamento de Microbiología Molecular, Instituto de Biotecnología, Universidad Nacional Autónoma de México, Apdo. Postal 510-3, Cuernavaca, Morelos, México

\$Present address: Ecologie Systématique Evolution, CNRS, Université Paris-Sud, AgroParisTech, Université Paris-Saclay, Orsay, France

คPresent addresss: Department of Entomology, Hebrew University of Jerusalem, Rehovot, Israel

${ }^{ \pm}$Present address: Carrera de Biología, Faculta de Estudios Superiores Zaragoza, UNAM, Mexico City, Mexico 
Data deposition: This Whole Genome Shotgun project has been deposited at GenBank under the accession

JMEH00000000. The version described in this paper is version JMEH001000000.1; BioSample SAMN02732272

\section{Abstract}

We report the genome sequence of Exiguobacterium chiriqhucha str. N139, isolated from a high-altitude Andean lake. Comparative genomic analyses of the Exiguobacterium genomes available suggest that our strain belongs to the same species as the previously reported $E$. pavilionensis str. RW-2 and Exiguobacterium str. GIC 31. We describe this species and propose the chiriqhucha name to group them. 'Chiri qhucha' in quechua means 'cold lake', which is a common origin of these three cosmopolitan Exiguobacteria. The 2,952,588-bp E. chiriqhucha str. N139 genome contains one chromosome and three megaplasmids. The genome analysis of the Andean strain suggests the presence of enzymes that confer E. chiriqhucha str. N139 the ability to grow under multiple environmental extreme conditions, including high concentrations of different metals, high ultraviolet B radiation, scavenging for phosphorous and coping with high salinity. Moreover, the regulation of its tryptophan biosynthesis suggests that novel pathways remain to be discovered, and that these pathways might be fundamental in the amino acid metabolism of the microbial community from Laguna Negra, Argentina. 
52

60

\section{Abbreviations}

HAALs: high altitude Andean Lakes $\quad$ ANI: Average Nucleotide Identity AAI: Average Amino Acid Identity

LM: Lake Medium

SSGs: Strain Specific Genes $\quad$ HGT: Horizontal Gene Transfer

BCAA: Branched Chain Amino Acids $\quad$ PER: Photoenzymatic Repair

NER: Nucleotide Excision Repair PRR: Post Replication Repair

9

The high altitude Andean Lakes (HAALs) from Puna, Argentina, are a group of lakes located at 3000-6000 meters above sea level which are characterized by high ultraviolet (UV) radiation and salinity, broad temperature variations, low nutrient concentrations and high contents of metals and metalloids, mainly arsenic (Fernández-Zenoff et al., 2006; Fernández-Zenoff, Siñeriz \& Farías, 2006; Dib et al., 2008; Flores et al., 2009; Ordoñez et al., 2009; Albarracín et al., 2011; Belfiore, Ordoñez \& Farías, 2013). These environmental conditions are considered to be extreme and might resemble those of the Earth's early atmosphere, as has been stated by NASA (Cabrol et al., 2007; Farías et al., 2009). Hence, these geographical areas have been proposed for studies on astrobiology (Farías et al., 2009). Despite being oligotrophic and hostile, a great microbial diversity has been found in the HAALs, where bacteria from the genus Exiguobacterium are one of the dominant taxa (Ordoñez et al., 2009, 2013; Sacheti et al., 2013). 
The Exiguobacterium genus, a sister clade to the Bacillus genus, is currently underexplored, and molecular studies of this genus from different sources are limited (Vishnivetskaya, Kathariou \& Tiedje, 2009). Exploring Exiguobacterium strains is of great significance because understanding their strategies to adapt to diverse and extreme environmental conditions will likely place them as model organisms involved in the remediation of organic and inorganic pollutants. In particular, Exiguobacterium strains isolated from the HAALs have the potential of becoming an attractive model system to study environmental stress responses, as these microorganisms are able to grow efficiently in the laboratory (Ordoñez et al., 2009; Belfiore, Ordoñez \& Farías, 2013). Moreover, Dib et al. suggested that these microorganisms could harbor various stress defense associated systems (Dib et al., 2008).

The Exiguobacterium chiriqhucha str. N139 was selected for genome sequencing due to its stress defense mechanisms such as its tolerance to high UV-B radiation, salinity and metalloids, particularly arsenic. This strain was isolated from the water column of Laguna Negra, which belongs to the 'Salar de la Laguna Verde', a system of five shallow oligotrophic lakes originated in the Tertiary (65 million to 1.8 million years ago) (Ericksen \& Salas, 1987).

In the present study we characterized the genome of E. chiriqhucha str. N139, in order to identify the strategies that this organism employs to cope with the extreme environmental factors present in the aforementioned lake, mainly those related to metal and UV-B resistance. We also performed comparative genomics focusing on the two strains that would comprise the same species as Exiguobacterium chirqhucha str. N139; E. pavilionensis str. RW-2, isolated from the permanently cold Pavilion Lake in Canada (White III, Grassa \& Suttle, 2013) and Exiguobacterium str. GIC31 isolated from a glacier in Greenland (Vishnivetskaya et al., 2014). 
95 Since the three strains were isolated from cold lakes, we propose the name 'chiri qhucha', which

96 means 'cold lake' in quechua, the Andean prehispanic language.

97

\section{Classification and features}

Members of the Exiguobacterium genus are Firmicutes, Gram-positive, facultative anaerobes with a low G + C content (Vishnivetskaya, Kathariou \& Tiedje, 2009). Exiguobacterium is widely distributed all over the world (Karami et al., 2011) and has been isolated and typified from a wide variety of environments including hot springs (Vishnivetskaya, Kathariou \& Tiedje, 2009; Vishnivetskaya et al., 2011), hydrothermal vents (Crapart et al., 2007), permafrost (Vishnivetskaya \& Kathariou, 2005; Vishnivetskaya et al., 2006; Rodrigues et al., 2008), marine sediment (Kim et al., 2005), oligotrophic environments (Rebollar et al., 2012), biofilms (Carneiro et al., 2012), alkaline methanogenic microcosms (Rout, Rai \& Humphreys, 2015) and more recently in water and microbial mats from high-altitude desert wetlands (Ordoñez et al., 2013). The Exiguobacterium genus is divided in two main phylogenetic clades (Vishnivetskaya, Kathariou \& Tiedje, 2009); clade I is composed of temperate and cold-adapted strains, whereas clade II includes alkaliphilic species, with a marine origin and/or from high-temperature habitats (Figure 1A).

E. chiriqhucha str. N139, which belongs to clade II, was isolated from the water column of Laguna Negra, in the HAALs (GPS: $27^{\circ} 38^{\prime} 49^{\prime}$ S, 68³2'43” W) and in laboratory conditions can uptake a wide variety of carbon sources (Table S1). Its cells are short rods and do not sporulate (Figure 2, Table 1). 
115 Materials and Methods

116

Growth conditions and genomic DNA preparation

E. chiriqhucha str. N139 was isolated from Laguna Negra by plating it in Lake Medium

120

121

122

123

124

125

126

127

128

129

130

131

132

133

134

135

\section{Microscopy}

Differential interference contrast (DIC) images were obtained from cells grown on LB medium overnight, and mounted in No. 2 coverslips (Figure 2). LB medium was used as mounting media during image acquisition. Images were shot with an Olympus FV1000 Laser Scanning Confocal on an Olympus IX81 inverted microscope equipped with 60x UPlanSApo NA 1.3 Sil objective lens. With a 405nm laser line, DIC Images were acquired in the TD channel controlled with Olympus FV10-ASW-4.2 software. Brightness, contrast and scale bars were adjusted on displayed images using the Fiji software.

\section{Phylogenetic Reconstruction}

The complete genomic sequences of 17 representative Exiguobacterium strains were used to reconstruct their phylogeny with PhyloPhlAn. This software extracts a set 31 manually curated 
136 conserved proteins from each genome, aligns them, keeps the positions that retain important 137 evolutionary information and builds a phylogenetic tree (Segata et al., 2013). Figure 1A shows this 138 phylogenetic reconstruction of the selected Exiguobacterium genomes from both clades.

139 Genome sequencing and assembly

140 The genome of E. chiriqhucha str. N139 was generated using 454 technology (Table 2). A

141 standard 454 Titanium library was constructed and sequenced, producing 664,086 reads, totaling 142 253.9 Mb of data. Phred quality cut-off was set to 20. The 454 data was assembled with Newbler, 143 version 2.8 and MIRA, version 3.4 (Chevreux et al., 2004). The GS De Novo Assembler GUI was 144 used, parameters selected were minimum read length of 45 and output scaffolds file. The 145 146 147 148 149 150

parameters used for the MIRA assembly were: number of passes of 1 and no uniform read distribution nor trimming of overhanging reads. Warning message for read names longer than 40 was deactivated. Both assemblies were merged using Minimus2, from the amos version 3.1.0, with assembly errors manually corrected. The contigs were sorted with Mauve version 2.3.1 (Rissman et al., 2009), using Exiguobacterium sp. AT1b as the reference because it is the closest relative with a completely sequenced genome (Vishnivetskaya et al., 2011).

\section{Genome annotation}

Protein-coding genes, tRNAs, rRNAs and non-coding RNAs were identified using the annotation pipeline Prokka (Seemann, 2014), followed by annotation refinement with InterProScan (Quevillon et al., 2005). Riboswitches were identified with the Infernal 1.1 package (Nawrocki \& Eddy, 2013) using the corresponding covariance models from the Rfam database (Burge et al., 2013). COGs were assigned by profile hidden Markov model (profile HMM) searches using the hmmsearch program of the HMMER3 package (Mistry et al., 2013). For every 
158

159

160

161

162

163

164

165

COG, a multiple sequence alignment of bona fide representative sequences were generated using the Muscle program (Edgar, 2004), and then, the corresponding Hidden Markov Model was built using the hmmerbuild program, also provided in the HMMER3 package (Mistry et al., 2013). The cutoff E-value in the hmmsearch process varies importantly for every COG. For every one of the COG groups we have defined a high confidence cutoff E-value value defined as the highest Evalue (smallest bit score) observed for the members of such COG. In any case, none of the COG cutoff E- values was greater than 1e-10. The resulting annotation was subjected to manual curation. Pathway Tools 13 (Karp et al., 2009) in combination with the BioCyc (Caspi et al., 2014) and UNIPROT (Consortium, 2015) databases were used to infer the metabolic capacities of $E$. chiriqhucha str. N139. The curated model of E. chiriqhucha str. N139 can be provided upon request, and will be deposited in the BioCyc database.

\section{Clustering of strains into a single species}

Phylogenetic analyses, ANI and AAI calculations, synteny analyses, as well as pangenome reconstruction were performed in order to a better understanding of the taxonomic position of the strain N139 isolated from Laguna Negra, relative to all the Exiguobacterium genomes available at the time of analysis.

ANI and AAI calculations (Goris et al., 2007) were done with default parameters for N139 versus all other complete genomic sequences of Exiguobacterium as well as pairwise comparisons for the three closest strains using the web server from Kostas lab http://enve-omics.ce.gatech.edu/ with default parameters. Comparisons to Exiguobacterium str. N139 can be seen in Table S2.

To explore the genomic rearrangements present on E. chiriqhucha str. N139 in comparison to other Exiguobacterium species, nucleotide syntenic blocks were obtained with Mauve version 
180 181 182 183 184

2.3.1 (Darling et al., 2004). Syntenic block permutations were exported and used as input for $M G R$ (Bourque \& Pevzner, 2002). $M G R$ was used to calculate the minimum number of rearrangements between the species analyzed, and to recover the rearrangement dendrogram. genoPlotR (Guy, Kultima \& Andersson, 2010) was used to plot the syntenic blocks (Figure 1B).

The pangenome of the nine Exiguobacterium genomes from clade II available at the time was reconstructed to aid in the taxonomic positioning of the strain N139. Orthologs were first calculated following the OrthoMCL pipeline (Li, Jr \& Roos, 2003; Fischer et al., 2011), and the pangenome and the core genome were elucidated using ad hoc perl scripts. The selected strains were $E$. str. AT1b isolated from a hot spring in Yellowstone, USA (Vishnivetskaya et al., 2011); E. marinum, isolated from the Yellow Sea, South Korea (Vishnivetskaya et al., 2014); E. aurantiacum, from a potato processing plant, in the UK (Vishnivetskaya et al., 2014); E. str. 811-1 isolated from a salt lake in Inner Mongolia, China (Jiang et al., 2013); E. sp. S17 from the Laguna Socompa, another HAAL, Argentina (Ordoñez et al., 2013); E. mexicanum isolated from a brine shrimp Artemia franciscana (López-Cortés et al., 2006); E. pavilionensis (now chiriqhucha) str. RW-2 isolated from Pavilion Lake, Canada (White III, Grassa \& Suttle, 2013) and $E$. (now chiriqhucha) str. GIC31, isolated from glacier ice in Greenland (Vishnivetskaya et al., 2014). 
202 strains and Exiguobacterium str. N139 were grown in $40 \mathrm{~mL}$ of LB medium under shaking (150

$203 \mathrm{rpm})$ at $30^{\circ} \mathrm{C}$ and cells were harvested by mid log phase $\left(\mathrm{OD}_{600 \mathrm{~nm}} 0.5\right)$ by centrifugation at 8000

$204 \mathrm{rpm}$ for $10 \mathrm{~min}$ at $4^{\circ} \mathrm{C}$. The pellets were washed twice with $30 \mathrm{~mL}$ of $0.9 \% \mathrm{NaCl}$, and resuspended

205 in the same volume of $40 \mathrm{~mL} .20 \mathrm{~mL}$ of cell suspensions were transferred into sterile quartz tubes

206 (16 cm long and $1.8 \mathrm{~cm}$ diameter) and placed horizontally to ensure maximal exposure and 207 incubated at $15^{\circ} \mathrm{C}$ under gentle shaking $(150 \mathrm{rpm})$.

Tubes were irradiated from a distance of $30 \mathrm{~cm}$ with UV-B doses between 2,0 - 3,0 W/m2 during 240 min (09815-06 lamps, Cole Parmer Instrument Company; major emission line at 312 $\mathrm{nm})$. Tubes were covered with an acetate sheet to block out UV-C. Irradiance was quantified with a radiometer (09811-56, Cole Parmer Instrument Company) at $312 \mathrm{~nm}$ with half bandwidth of 300 to $325 \mathrm{~nm}$. Aliquots of $0.1 \mathrm{~mL}$ were taken at different exposure times $(0,60,120,180$ and 240

min). Samples were then serially diluted in LB broth and spread in duplicate on Petri dishes with

214

the same medium to determine the number of colony forming units (CFU). Controls of unexposed samples were run simultaneously in darkness and the percentage of cell survival after each treatment was calculated relative to these controls.

\section{Results and Discussion}

\section{Genome Properties}

The final assembly of the genome of E. chiriqhucha str. N139 consists of 23 contigs, the smallest one being 457 bases in length and the largest $1.5 \mathrm{Mb}$, with an average coverage of $85 \times$. Its genome includes three circular megaplasmids with probable sizes of $250.57,137.48$ and $48 \mathrm{~Kb}$, as determined by Pulse Field Gel Electrophoresis (PFGE) analysis (see Figure S1 and Supplemental Material) and one circular chromosome with an estimated size of 2,516 kb, with a 
$22452 \%$ GC content. A total of 3,182 genes were predicted $(3,049$ protein-coding genes and 82

225 noncoding RNA genes (95.8\% and 2.57\% respectively)). E. chiriqhucha str. N139 has 10

226 ribosomal rRNA operons, confirmed by PFGE (see Supplemental Material and Figure S2). A

227 putative function was assigned to $2,214(73 \%)$ of the protein-coding genes, and the remaining

228 genes were annotated as hypothetical proteins. The properties and the statistics of the genome are

229 summarized in Table 3. 2,575 protein-coding genes were assigned to 1,603 COG families, 230 corresponding to a gene content redundancy of $38.1 \%$ (see Table 4).

\section{Genome Rearrangements}

Genome rearrangements within clades I and II are scarce, showing high conservation of the genomic structure within clades. However, several genomic rearrangements occurred as both clades diverged.

In order to determine which contigs of E. chiriqhucha str. N139 belong to plasmids, the plasmid sequences of pEspA and pEspB from E. arabatum RFL1109 (Jakubauskas et al., 2009) were retrieved from NCBI. This strain was selected for comparison because their plasmids have been widely studied (Jakubauskas et al., 2009) and because it is phylogenetically close to $E$. chiriqhucha str. N139. Jakubauskas and colleagues identified the regions hr-A1, hr-AB and hr-A2 in plasmid pEspA as capable of replicating the plasmid in Bacillus. For plasmid pEspB, they hypothesized that the regions $\mathrm{hr}-\mathrm{B} 1, \mathrm{hr}-\mathrm{AB}$ and $\mathrm{hr}-\mathrm{B} 2$ are involved in a theta replication mechanism (Jakubauskas et al., 2009). BLAST searches of these regions were performed against all Exiguobacterium genome sequences available to date. For the strains E. MH3, E. antarcticum and E. sp. AT1b, which are described as genomes without plasmids, no significant hits were found. Conversely, hits to the E. arabatum sequences hr-B1, hr-AB and hr-B2 (a fragment of $39 \mathrm{~kb}$ ) were 
246 found in the genomes of $E$. GIC31 $(56 \mathrm{~kb})$ and $E$. N139 (contig000014 of size $25 \mathrm{~kb}$ ). It was 247 concluded that the sequences present in the plasmids are shared within different Exiguobacterium 248 strains, displaying a highly dynamic behavior. Therefore it was not possible to determine which 249 of our contigs correspond to the three megaplasmids observed in the PFGE experiments (see 250 Supplemental Material). Furthermore, contig 14 in our assembly corresponds to the smallest contig 251 of E. GIC31, so it could be a plasmid in both Exiguobacterium strains. Genes belonging to contig 25214 are mostly hypothetical proteins, only 11 genes could be annotated. Of these, 9 correspond to 253 254 255 256 257 258 259 260 261 262 263 264 genes involved in mobile elements (antirestriction proteins, integrases and transposases), conjugal transfer proteins and competence factors; one antibiotic resistance gene and a RNaseH. However, contig 14 lies adjacent to contig 13, both accounting for a total size of $100 \mathrm{~kb}$ when synteny was evaluated against E. pavillionensis RW-2. It is worth mentioning that contig 13 possesses most of the genes responsible for metals resistance, but this region appears to be integrated in the chromosome of $E$. GIC31. This highly dynamic behavior across strains, along with the presence of several genes involved in mobility, suggests that, if both contigs belong to a plasmid, it might be an integrative one. A MAUVE analysis performed between the strains N139, GIC31 and $E$. pavillionensis RW-2 shows high synteny across their chromosomes. This idea that contigs 12,13 and 14 might belong to the plasmids is supported by their shifts in GC skew (Figure 3). To all appearances, the chromosomes within each of the two main clades of the Exiguobacterium species are very similar, but quite distinct when compared between these clades (Figure 1).

The Exiguobacterium strain N139 belongs to the chiriqhucha species along with $E$. pavilionensis str. RW-2 and Exiguobacterium sp. GIC31

A phylogenomic reconstruction (Figure 1A) placed the strain N139 as most similar to Exiguobacterium str. GIC31 (Vishnivetskaya et al., 2014) as well as to E. pavilionensis str. RW-2 
269 (White III, Grassa \& Suttle, 2013). ANI and AAI calculations of all clade II Exiguobacterium 270 strains were performed and compared to our N139 strain, suggesting that E. pavilionensis str. RW2, Exiguobacterium sp. GIC31 and this N139 strain belong to the same species since they share ANI values above $97 \%$ (Table S2) (Goris et al., 2007). Typically, the ANI values between genomes of the same species are above 95\% (e.g., E. coli). ANI and AAI scores of all pairwise comparisons of the three proposed Exiguobacterium chiriqhucha strains exceed the 97\% threshold (data not shown). Also relying on the ANI and AAI calculations, it was concluded that the outgroup of the E. chiriqhucha species could be E. mexicanum.

\section{Exiguobacterium clade II pangenomes}

To further understand the genomic properties of E. chiriqhucha str. N139 and its taxonomic positioning, we built the pangenome of nine Exiguobacterium strains from clade II, whose complete genomes were available at the time of analysis. This pangenome is composed of 5,267 genes; 2,116 of them belonging to the core genome and 1,664 being Strain Specific Genes (SSGs). The resulting pangenome shows a very conserved and cohesive pool of genes, despite their evolutionary distance and their remote geographic locations. Over two thousand genes compose the core genome, which represents a large core genome when compared to other pangenomes, and taking into account that the average genome size of Exiguobacterium strains, which is approximately three thousand genes. The SSGs are represented in a heatmap on Figure S3 where the clusterization of the Exiguobacterium strains is based on the presence (and abundance) or absence of their COG assignation. Exiguobacterium sp. S17 and E. mexicanum are exceptional for the fact that they possess a large pool of SSGs (Table S3). We speculate that some of these SSGs could have been acquired by Horizontal Gene Transfer (HGT) and retained to adapt to these 
291

292

diverse environments, or equally likely, lost in some of the living taxa, due to lack of selective pressure in their respective niches.

Fifty-nine of the SSGs found in the E. chiriqhucha str. N139 were mapped on its genome to see if their distribution followed some bias (Figure 3). Throughout the contigs that are putative chromosomal regions, the SSGs appear to be randomly distributed. However, some of the SSGs are concentrated in the contigs 12 and 13, supporting the previous idea that these contigs may be part of the megaplasmids seen in the PFGE analysis (Figure S1). COGs were assigned to the SSGs as previously described for the E. chiriqhucha str. N139 genome. For the whole set of SSGs of the pangenome, COGs were successfully assigned to $66 \%$ of the genes, and are represented in a heatmap (Figure S3). However, most of the N139 SSGs could not be assigned to COGs, and for those that were successfully classified, the vast majority falls in the S and R (Poorly Characterized) COG categories, leaving open questions on which may be the unique strategies that N139 employs to adapt to the particular environment of Laguna Negra.

\section{Main Metabolic Pathways, Amino acids, Nucleotides and Cofactors}

Based on its genomic content, E. chiriqhucha str. N139 is probably a chemoheterotroph since it has two copies of $a i o B$ arsenite oxidase, which means it could obtain energy from arsenite oxidation. It has the complete pathway for glycolysis and it could synthesize acetyl-CoA, succinylCoA and isobutanoyl-CoA. It is a heterolactic fermenter, being able to produce lactate from pyruvate and ethanol from acetaldehyde. It has a complete TCA cycle, and it lacks the first two steps of the pentose phosphate pathway, but the rest of the pathway is present. Hence, its central metabolism is similar to B. subtilis (Blencke et al., 2003, 2006), but E. chiriqhucha str. N139 can synthesize more fermentation products, namely ethanol and formate. E. chiriqhucha str. N139 lacks the routes for synthesizing de novo phenylalanine and tyrosine, as well as the Branched Chain 
314 Amino Acids (BCAA). However, it can synthesize tyrosine from phenylalanine, since it has the 315 phenylalanine-4-hydroxylase regulated by a Tyr (UAC codon) T box riboswitch. Despite lacking 316 the complete pathways for BCAA biosynthesis, it preserves the ilvE gene, a BCAA aminotransferase, which could probably synthesize any of the three BCAAs from available precursors. An interesting note on its tryptophan biosynthesis is that its biosynthetic operon is split in two transcription units: $\operatorname{trp} E G$ and $\operatorname{trp} D C F B A$, which are separated in the chromosome, but coregulated by a Trp $\mathrm{T}$ box riboswitch. Although this regulation is common in Firmicutes (GutierrezPreciado et al., 2005; Gutiérrez-Preciado, Yanofsky \& Merino, 2007), the genome context of the trp operon is not, and it is interesting that this separation takes place at the synthesis of anthranilate. Moreover, the $\operatorname{trpEG}$ genes are regulated by a single $\mathrm{T}$ box, whilst the $\operatorname{trpDCFBA}$ operon is regulated by two $\mathrm{T}$ boxes in tandem. This could either mean that the separation of the pathway is a recent event and the regulation is being settled in order to coordinate both transcriptional units; or that this strain requires anthranilate (the product of $\operatorname{trp} E G$ ) for something else. Certainly, one possibility is that E. chiriqhucha str. N139 exports anthranilate for a synthrophy with a partner(s) and the subsequent steps of the tryptophan biosynthetic pathway require a stricter regulation in order for the genes trpDCFBA to be expressed. Since E. chiriqhucha str. N139 lacks the biosynthetic pathways for five amino acids, a likely scenario is that this bacterium is sharing metabolites with other partners in Laguna Negra. This is supported by the observation that it is able to form part of a biofilm, and that in all of the amino acids tested it can only grow on serine and asparagine as a sole carbon source (see Table S1). Based on the metabolite tracer from Pathway Tools, it can be inferred that E. chiriqhucha str. N139 could synthesize phenylalanine as well as valine from serine or asparagine. In the same fashion, it cannot grow with phenylalanine as the sole carbon source. Therefore, the configuration of the genes involved in amino acid 
337

338

metabolism might represent a requirement of amino acid syntrophy that needs further exploration and testing. A second possibility is that E. chiriqhucha str. N139 is utilizing anthranilate for some novel pathway. Anthranilate cannot be in excess with respect to tryptophan, since its excess could decrease the availability of phosphoribosyl pyrophosphate (PRPP) for histidine synthesis (and other reactions) (Merino, Jensen \& Yanofsky, 2008). This novel pathway could be involved in different functions that require either tryptophan or anthranilate as intermediates. Examples of these functions are quorum sensing molecules in Pseudomonas aeruginosa (Farrow \& Pesci, 2007), plant hormones in Azospirillum brasilense (Ge, Xie \& Chen, 2006), violacein in Chromobacterium violacein (Antônio \& Creczynski-Pasa, 2004) or antibiotics as in Streptomyces coelicolor (Amir-Heidari, Thirlway \& Micklefield, 2008).

The regulation of biosynthetic and transporter genes through riboswitches is common in Firmicutes, specially the members of Bacilli class. It has also been observed that transport and biosynthesis of the same metabolite tend to be part of a regulon mediated by in cis elements, like riboswitches (Gutiérrez-Preciado et al., 2009). Methionine can be synthesized and imported through several strategies. Several SAM riboswitch regulated operons coding for Met transporters were identified in the genome of E. chiriqhucha str. N139, as well as canonical met biosynthetic genes. An interesting case is the methionine salvage pathway, whose genes are encoded in two divergent operons, both regulated by divergent SAM riboswitches. Both operons must be transcribed in order for the Yang cycle to be completed. In one operon, genes $m \operatorname{tn} K$ and $m t n A$ are transcribed along with three ribose transporters, $r b s B$, $r b s C$ and $a r a G$. Lysine biosynthesis (from aspartate via diaminopimelate) and transport are part of a regulon under the lysine riboswitch. Furthermore, through the identification of riboswitches, two transporters from the NhaC family were annotated: one as a methionine transporter (SAM riboswitch), and the other one as a lysine 
transporter (LYS riboswitch). This strategy of improving gene annotation through the knowledge of the gene's regulation has been previously explored (Rollins, 2002; Gutiérrez-Preciado \& Merino, 2012; Gutiérrez-Preciado et al., 2015).

Cofactors. Thiamine can be synthesized de novo, its biosynthesis and its uptake are regulated by the TPP riboswitch. Moreover, the analysis of E. chiriqhucha str. N139 genome indicates that a new thiamine transporter could be present in this bacterium. The gene exiN139_02072 is automatically identified as a membrane protein, but it seems to be regulated by a TPP riboswitch. Experimental evidence is needed for the confirmation and characterization of this transporter, which could unveil a new family of thiamine transporters. Riboflavin biosynthesis and transport (RibU) are also co-regulated through a FMN riboswitch.

Nucleotides. In the genome of E. chiriqhucha str. N139 the purine de novo biosynthetic pathway is encoded in a huge transcription unit regulated by a purine riboswitch. Other transcription units in the same regulon include a monocystronic GMP synthase, and genes involved in adenine and adenosine salvage pathway.

\section{Genomic Adaptations to an Extreme Environment}

Laguna Negra is an aquatic ecosystem that harbors extreme environmental conditions such as high levels of UV-B (10.65 wm2), high salinity levels (32\%), scarce nutrients, particularly phosphorous $(<005 \mathrm{mg} / \mathrm{l})$, high metal contents including the metalloid arsenic $(3 \mathrm{mg} / \mathrm{l})$, an alkaline $\mathrm{pH}$ and large daily temperature fluctuations (ranging from $20^{\circ} \mathrm{C}$ during the day to $-40{ }^{\circ} \mathrm{C}$ at night) (Flores et al., 2009); (see Table 1). 
380

381

382

383

384

385

386

387

388

389

390

391

392

393

394

395

396

397

\section{Resistance to metals and metalloids}

In Laguna Negra, ubiquitous Arsenic enters the E. chiriqhucha str. N139 cells through existing transporters due to its high structural similarity with other molecules (Rosen, 1999) and induces oxidative stress responses (Oremland \& Stolz, 2003). Furthermore, arsenite $\left(\mathrm{AsO}_{2} \mathrm{H}\right)$ and arsenate $\left(\mathrm{AsO}_{4}{ }^{3-}\right)$, are both toxic molecules. Arsenite binds to reduced cysteines in proteins inactivating them, and arsenate is a molecular analog of phosphate and therefore inhibits oxidative phosphorylation (Oremland \& Stolz, 2003). Arsenate is far less toxic than arsenite, hence the oxidation of arsenite is considered a detoxification process. However, the oxidation of arsenite to arsenate, when coupled to the reduction of oxygen to water, is an exergonic process, and it has been suggested that at least some bacteria may derive energy out of this process (vanden Hoven \& Santini, 2004). E. chiriqhucha str. N139 has an arsenite oxidase, AioB, enabling it to oxidize arsenite. This is an important metabolic capability, because it uses arsenite as an electron donor. Moreover, from a bioremediation point of view, this former metabolic feature is important since arsenite is more soluble than arsenate, so it can facilitate the removal of As in solution. $E$. chiriqhucha str. N139 also has an arsenite efflux pump, ArsB, as well as an ATPase that provides energy to ArsB for extrusion of arsenite and antimonite, ArsA, co-transcribed with ArsD, an arsenic chaperone for the ArsAB pump (Páez-Espino et al., 2009). Hence, this bacterium can probably detoxify and extrude As, as well as oxidize arsenite acquiring energy from this process. These ArsAB and ArsD proteins are also present in Salinivibrio strains isolated from the Laguna Socompa. However, these Salinivibrio strains also have ArsC, a cytoplasmic oxidoreductase that reduces arsenate to arsenite in a ATP-glutathione-glutaredoxin dependent way (Gorriti et al., 2014). E. chiriqhucha str. N139 lacks significant homologs to this gene as well as significant homologs to $B$. subtilis' ars $C$ gene. 

four paralogous copies of merA. Briefly, MerA is the key detoxification enzyme of the mercury resistance system, reducing $\mathrm{Hg}^{2+}$ to $\mathrm{Hg}^{0}$ (Silver \& Phung, 2005). $\mathrm{Hg}$ is toxic due to its high affinity to sulfur (Nies, 2003) and usually, mer resistance genes are co-transcribed in an operon whose dissemination is common by horizontal gene transfer (HGT) (Barkay, Miller \& Summers, 2003). In this organism, two copies of mer $A$ are present in a monocystronic fashion; a third one is transcribed with a hypothetical protein. A fourth copy is co-transcribed with merR, the regulatory protein of the system. Two mer transporters which uptake $\mathrm{Hg}$ and merP, a transporter with a Sectype signal, which could import $\mathrm{Hg}$ as a neutral chloride or hydroxide and deliver it to the other Mer transporters, which will finally transfer it to MerA.

The most common mechanism of resistance to metals consists of efflux pumps for inorganic ions. However, As and $\mathrm{Hg}$ resistance mechanisms are unique in the sense that these elements are reduced to lower their toxicity (Silver \& Phung, 2005), instead of being exported. $E$. chiriqhucha str. N139 is resistant to cadmium, zinc, cobalt, and copper by pumping it out from the cell. It has two membrane embedded $\mathrm{Cd}^{2+}$ efflux pumps, one of which can also extrude zinc and cobalt; two paralogous copies of $\operatorname{cop} A$ and $\operatorname{cop} B$, two P-type ATPase systems for exporting copper, and cueR, a sensing cytoplasmic $\mathrm{Cu}$ that protects periplasmic proteins from copper-induced toxicity (Orell et al., 2010). copB is transcribed monocystronically, and each of the cop $A$ genes form an operon co-transcribed with a copy of $\operatorname{cop} Z$, a copper chaperone, but one is co-transcribed with a glutaredoxin, whilst the other is co-transcribed with $c s o R$, a copper-sensitive operon repressor.

Additionally, this microorganism lives in a low phosphorous environment, and relies on strategies for phosphorous uptake, like the presence of high-affinity Pi transporters and its 
426 regulation ( $p s t S$, pstCAB, phoB, phoR, $\operatorname{ded} A$ and $p t r A$ ) and genes for polyphosphate storage and

427 breakdown ( $p p k$ and $p p x)$. Organisms that scavenge phosphate can sometimes uptake the 428 structurally similar arsenate ion, and hence also depend on arsenate detoxification mechanisms. It 429 is also able to thrive in the alkaline environment of Laguna Negra since its genome code for all the 430 typical antiporters present in alkaliphilic bacilli (nhaC, nhaP, the mpr operon, yhaU, norM and $m l e N)$. These antiporters present also contribute to a moderate salinity resistance this could also be related with the maintenance of metal resistance strategies in its genome, since it has been shown that lowering the salinity can lead to enhanced sensitivity to cadmium, cobalt and copper

\section{Resistance to UV radiation}

Another extreme environmental condition in Laguna Negra is high ultraviolet radiation, particularly UV-B (Flores et al., 2009; Ordoñez et al., 2009). In order to determine if $E$. chiriqhucha str. N139 can cope with this constant stress, we measure the effect of colony survival of different Exiguobacterium strains exposed to UV-B radiation (Figure 4). More than 25\% of the colonies survive after $3 \mathrm{hrs}$ of constant UV-B radiation. This contrasts with the other Exiguobacterium strains which rapidly start to decay, even though one of them, str. S17 was isolated from a neighbor lake, Laguna Socompa, in the HAALs (Ordoñez et al., 2013).

Bacteria have different UV damage repair pathways, including photoenzymatic repair (PER), nucleotide excision repair (NER) also called dark repair, and recombinational repair (PRR) or post-replication repair (Goosen \& Moolenaar, 2008). E. chiriqhucha str. N139 has three genes (exiN139_00335 (phrB), exiN139_01768 and exiN139_00235) related to photolyases, which are involved in PER. They use UV as energy source (using FADH and transferring electrons) and 
448 catalyze the monomerization of cyclobutyl pyrimidine dimers. The gene exiN139_00335 only has

449 homologues in Firmicutes including other known Exiguobacterium, and exiN139_01768 has

450 homologues in Firmicutes, Cyanobacteria, $\alpha$ - and $\gamma$ - Proteobacteria, and Euryarcheotes.

451 Additionally, exiN139_00235 is a cryptochrome, which are flavoproteins related to photolyases.

452 Cryptochromes do not repair DNA and are presumed to act in other (unknown) processes, such as

453 entraining circadian rhythms (Yuan et al., 2012). It is worth to remark that from these proteins

454 only exiN139_01768, annotated as Deoxyribodipyrimidine photo-lyase-related protein, contains

455 significant homologs in the genomes of the two Exiguobacterium compared in the UV-B radiation

456 resistant assay (Figure 4).

E. chiriqhucha str. N139 has also genes for NER. Its genome encodes the UvrABC endonuclease, a complex that recognizes DNA damage, binds to the damaged segment and cleaves it. Additionally, it codes for PcrA (also known as UvrD), a helicase in charge of removing the excised segment recognized and cleaved by UvrABC. These genes are regulated by the SOS response, which uses LexA as a repressor inactivated by RecA (Minko et al., 2001). E. aurantiacum and $E$. str. S17, contain homologs for the $u v r B / u v r C$ gene, and the $p c r A$ and $\operatorname{rec} A$ regulatory genes.

Regarding the PRR, E. chiriqhucha str. N139 encodes for RecA, which recognizes SSB and cleaves UmuD, which becomes UmuD' and binds UmuC to generate polymerase $\mathrm{V}$, which in turn repairs damages, sometimes causing mutations. The gene exiN139_03003 may produce polymerase IV that is also involved in DNA damage repair (Sommer, Bailone \& Universitaire, 1998). UmuC is found in the genome, however UmuD is missing. It is possible that a protein highly similar to an existing copy of LexA may be taking its role, given that both can be cleaved 
470

471

472

473

474

475

476

477

478

479

480

481

482

483

484

485

486

487

488

489

490

491

by RecA and are present in Exiguobacterium. UmuD and UmuC are not present in the genomic sequences of E. aurantiacum and E. str. S17.

E. chiriqhucha str. N139 appears robust towards UV-B radiation, possessing several mechanism to cope with this constant stress. Moreover, the two strains proposed to be part of the same chiriqhucha species, E. pavilionensis str. RW-2 and E. str. GIC31, contain the same set of genes described above to cope with UV-B radiation, another unifying property of these strains. The strains RW-2 and N139 contain two homologs for Deoxyribodipyrimidine photo-lyases, while GIC31 contains three.

8

\section{Living in syntrophy?}

Finally, it is likely that E. chiriqhucha str. N139 participates in biofilm formation in Laguna Negra along with other bacteria (unpublished results). Analyses of other Exiguobacterium have shown that they participate in marine biofilms interacting with other Firmicutes and Proteobacteria (López et al., 2006; Carneiro et al., 2012). Evidence of possible biofilms associated genes originates from two loci present in the genome of E. chiriqhucha str. N139. The first locus encoding a protein capable of producing alginate, a linear co-polymer of two uronic acids that is produced in its acetylated form by some bacteria for adherence of these bacteria to target cell walls by the creation of a biofilm (Ramphall \& Pier, 1985). The second locus codes for the arginine deiminase system, which can function at very low $\mathrm{pH}$ and is thought to be a critical factor in oral biofilm pH homeostasis (Burne \& Marquis, 2000).

\section{Conclusions}

E. chiriqhucha str. N139 lives in a high-altitude, salted lake exposed to intense UV radiation, about $300 \mathrm{~km}$ away from the nearest ocean, the Pacific. Many factors in E. chiriqhucha 
492 str. N139 metabolism, such as the its needs to uptake certain intermediates like phenylalanine and

493 BCAAs, and the possible excretion of the overproduced anthranilate, suggest that it is a key player

494 in the amino acid metabolism of a microbial consortium that inhabit Laguna Negra. Moreover, the

495 excess of anthranilate that it may produce could be directed to some novel pathway that remains

496 to be uncovered, such as a new antibiotic, a new pigment or a new quorum sensing molecule.

The genome of E. chiriqhucha str. N139 contains all the necessary strategies to cope with all the environmental stresses that simultaneously co-occur in Laguna Negra. This Exiguobacterium is able to detoxify metals like arsenic, mercury, cadmium, zinc, cobalt, and copper; it has a complete defense system against UV damage; and it is also able to thrive in the alkaline environment of Laguna Negra. (Ventosa, Nieto \& Oren, 1998). With all these characteristics, E. chiriqhucha str. N139 is an excellent candidate for future biotechnological research.

$$
\text { its genome we have gained insights on the strategies the strain N139 employs for thriving in its }
$$
habitat. From its Strain Specific set of genes, only 23 out of 59 could be annotated and classified to a COG, and still, most of the COG-classified genes belong to the poorly characterized category. This set of genes of unknown function require further experimental work to completely unveil how the strain N139 is adapting to the extreme environment of Laguna Negra. 
513

514

515

516

517

518

519

520

521

522

523

524

525

526

527

528

529

530

531

532

Description of Exiguobacterium chiriqhucha sp. nov.

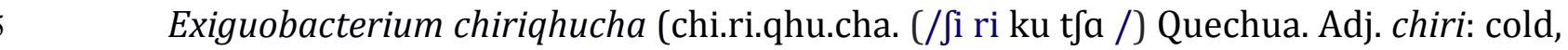
freezing; Quechua. Noun. qhucha: lake, pond. chiriqhucha of or belonging to a cold lake, referring to the common habitat of these three species). Members of the species Exiguobacterium chiriqhucha; inhabitants of freshwater ponds, saline ponds; distinguishable by their 16S rRNA sequences; accession numbers are: JMEH00000000 for the str. N139 genome, ATCL00000000 for the RW-2 genome (White III, Grassa \& Suttle, 2013) and JNIP00000000 for the GIC31 genome (Vishnivetskaya et al., 2014). The three strains that so far comprise this species form orange shiny colonies and are Gram-positive, rod-shaped, facultative anaerobes and motile via peritrichous flagella (Miteva, Sheridan \& Brenchley, 2004; Vishnivetskaya, Kathariou \& Tiedje, 2009; White III, Grassa \& Suttle, 2013). Two of them, str. RW-2 and str. GIC31 were isolated from permanently cold environments (Pavilion Lake and Glacier Ice, Greenland;(White III, Grassa \& Suttle, 2013; Vishnivetskaya et al., 2014)) whilst the str. N139 was isolated from Laguna Negra, a HAAL which temperature can drop to $-30^{\circ} \mathrm{C}$. Their temperature range of growth is from a minimum (str. GIC31) of $2^{\circ} \mathrm{C}$ to a maximum (str. RW-2) of $50^{\circ} \mathrm{C}$; the $\mathrm{pH}$ range for growth is from 5 to 11 in str. $\mathrm{RW}-2$ and from 7 to 9 in str. N139 (Miteva, Sheridan \& Brenchley, 2004; White III, Grassa \& Suttle, 2013). The three strains possess cold-shock proteins and have a $\mathrm{G}+\mathrm{C}$ content of $52 \%$ (White III, Grassa \& Suttle, 2013; Vishnivetskaya et al., 2014). The type strain is RW-2. 
533 Acknowledgements

534 We thank Jerome Verleyen for computer support and the Instituto de Biotecnología-

535 UNAM for allowing us access to its computer cluster. We would also like to thank Eric Nawrocki

536 for his guidance with the ssu-align program.

538 Tables

539 Table 1. Classification and general features of Exiguobacterium chiriqhucha str. N139

\begin{tabular}{|c|c|c|}
\hline Property & Term & Evidence code $^{\mathrm{a}}$ \\
\hline \multirow[t]{8}{*}{ Classification } & Domain Bacteria & TAS (Woese, Kandler \& Wheelis, 1990) \\
\hline & Phylum Firmicutes & TAS (Gibbons \& Murray, 1978) \\
\hline & Class Bacilli & TAS (De Vos et al., 2009) \\
\hline & Order Bacillales & TAS (De Vos et al., 2009) \\
\hline & Family Bacillales Family XII. Incertae Sedis & TAS (De Vos et al., 2009) \\
\hline & Genus Exiguobacterium & $\begin{array}{l}\text { TAS (De Vos et al., 2009; } \\
\text { Vishnivetskaya, Kathariou \& Tiedje, } \\
\text { 2009) }\end{array}$ \\
\hline & Species Exiguobacterium chiriqhucha & TAS (White III, Grassa \& Suttle, 2013) \\
\hline & Strain: N139 (Accession: JMEH00000000) & \\
\hline Gram stain & Positive & IDA \\
\hline Cell shape & Short rods & IDA \\
\hline Motility & Motile & IDA \\
\hline Sporulation & Non-sporulating & EXP \\
\hline Temperature range & Mesophilic $\left(30-37^{\circ} \mathrm{C}\right)$ & IDA \\
\hline Optimum temperature & $30^{\circ} \mathrm{C}$ & IDA \\
\hline $\mathrm{pH}$ range; Optimum & $7-9$ & IDA \\
\hline Carbon source & $\begin{array}{l}\text { B-Methylglucoside, Galacturonic acid, L- } \\
\text { asparagine, Tween 40, L-Serine, N-acetyl- } \\
\text { glucosamine, Hydroxybutyric acid, Itaconic } \\
\text { acid, Ketobutyric acid, Putrescine (See table } \\
\text { S1) }\end{array}$ & EXP \\
\hline Habitat & Aquatic & TAS (Flores et al., 2009) \\
\hline Salinity & $0.11 \%-10 \% \mathrm{NaCl}(w / v)$ & IDA \\
\hline Oxygen requirement & Facultatively anaerobic & TAS (De Vos et al., 2009) \\
\hline Biotic relationship & free-living & IDA \\
\hline Pathogenicity & non-pathogen & NAS \\
\hline Geographic location & Laguna Negra, Catamarca, Argentina & IDA \\
\hline Sample collection & 2006 & IDA \\
\hline
\end{tabular}




\begin{tabular}{lll}
\hline Latitude & $27^{\circ} 39^{\prime} 20.17^{\prime \prime} \mathrm{S}$ & IDA \\
\hline Longitude & $68^{\circ} 33^{\prime} 46.18^{\prime \prime} \mathrm{W}$ & IDA \\
\hline Altitude & $4100 \mathrm{masl}$ & IDA \\
\hline
\end{tabular}

${ }^{a}$ Evidence codes - IDA: Inferred from Direct Assay; TAS: Traceable Author Statement (i.e., a direct report exists in the literature); NAS: Non-traceable Author Statement (i.e., not directly observed for the living, isolated sample, but based on a generally accepted property for the species, or anecdotal evidence); EXP: Inferred from Experiment. These evidence codes are from the Gene Ontology project ("Gene Ontology Evidence Codes")

Table 2. Project information.

\begin{tabular}{ll}
\hline Property & Term \\
\hline Finishing quality & Permanent-draft \\
\hline Libraries used & 454 pyrosequence standard library \\
\hline Sequencing platforms & 454 Titanium \\
\hline Fold coverage & $85 \mathrm{x}$ \\
\hline Assemblers & Newbler 2.8 and MIRA 3.4 \\
\hline Gene calling method & Prokka \\
\hline Locus Tag & EF88 \\
\hline Genbank ID & JMEH00000000.1 \\
\hline GenBank Date of Release & December, 2015 \\
\hline GOLD ID & Go0093977 \\
\hline BIOPROJECT & PRJNA245187 \\
\hline Source Material Identifier & N139 \\
\hline Project Relevance & $\begin{array}{l}\text { OV resistance, metal resistance, adaptation to } \\
\text { oligotrophic environments }\end{array}$ \\
\hline
\end{tabular}

Table 3. Nucleotide content and gene count levels of the $E$. chiriqhucha str. N139 genome

\begin{tabular}{lrl}
\hline \multicolumn{1}{l}{ Attribute } & \multicolumn{1}{c}{ Genome (total) } \\
\hline \multicolumn{1}{l}{ Value } & \% of total ${ }^{\mathrm{a}}$ \\
\hline DNA coding (bp) & $2,952,588$ & - \\
\hline DNA G+C (bp) & $2,655,834$ & 89.94 \\
\hline DNA Scaffolds & \multicolumn{2}{c}{52} \\
\hline N50 & 23 & \\
\hline Total genes & $1,553,709$ & \\
\hline RNA genes & 3,182 & 100 \\
\hline Protein-coding genes & 82 & 2.62 \\
\hline Pseudogenes & 3,049 & 95.82 \\
\hline Genes in internal clusters & 26 & 0.81 \\
\hline
\end{tabular}




\begin{tabular}{lcc}
\hline $\begin{array}{l}\text { Genes with function } \\
\text { prediction }\end{array}$ & 2,356 & 74.04 \\
\hline Genes assigned to COGs & 2,575 & 80.92 \\
\hline $\begin{array}{l}\text { Genes with Pfam } \\
\text { domains }\end{array}$ & 2,538 & 79.76 \\
\hline $\begin{array}{l}\text { Genes with signal } \\
\text { peptides }\end{array}$ & NA \\
\hline $\begin{array}{l}\text { Genes with } \\
\text { transmembran helices }\end{array}$ & 888 & 27.90 \\
\hline CRISPR repeats & \multicolumn{2}{c}{0} \\
\hline
\end{tabular}

a) The total is based on either the size of the genome in base pairs or the total number of protein coding genes in the annotated genome.

Table 4. Genes associated with the 25 general COG functional categories

\begin{tabular}{cccl}
\hline Code & Value & \% of total $^{\mathbf{a}}$ & Description \\
\hline J & 166 & 5.44 & Translation, ribosomal structure and biogenesis \\
\hline A & 0 & 0 & RNA processing and modification \\
\hline K & 235 & 7.71 & Transcription \\
\hline L & 144 & 4.72 & Replication, recombination and repair \\
\hline B & 1 & 0.03 & Chromatin structure and dynamics \\
\hline D & 36 & 1.18 & $\begin{array}{l}\text { Cell cycle control, Cell division, chromosome } \\
\text { partitioning }\end{array}$ \\
\hline V & 62 & 2.03 & Defense mechanisms \\
\hline T & 166 & 5.44 & Signal transduction mechanisms \\
\hline M & 144 & 4.72 & Cell wall/membrane biogenesis \\
\hline N & 75 & 2.46 & Cell motility \\
\hline U & 53 & 1.74 & Intracellular trafficking and secretion \\
\hline O & 100 & 3.28 & $\begin{array}{l}\text { Posttranslational modification, protein turnover, } \\
\text { chaperones }\end{array}$ \\
\hline C & 152 & 4.99 & Energy production and conversion \\
\hline G & 232 & 7.61 & Carbohydrate transport and metabolism \\
\hline E & 224 & 7.35 & Amino acid transport and metabolism \\
\hline F & 84 & 2.76 & Nucleotide transport and metabolism \\
\hline H & 97 & 3.18 & Coenzyme transport and metabolism \\
\hline I & 81 & 2.66 & Lipid transport and metabolism \\
\hline P & 170 & 5.58 & Inorganic ion transport and metabolism \\
\hline Q & 54 & 1.77 & $\begin{array}{l}\text { Secondary metabolites biosynthesis, transport and } \\
\text { catabolism }\end{array}$ \\
\hline R & 463 & 15.19 & General function prediction only \\
\hline & & & \\
\hline S & 327 & 10.72 & Function unknown \\
\hline- & 447 & 15.55 & Not in COG \\
\hline
\end{tabular}

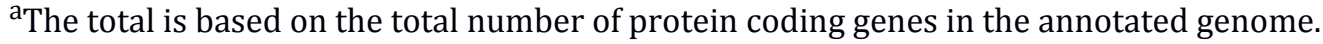


560 Figure Legends.

Figure 1. Evolutionary history of the genus Exiguobacterium. A) Phylogenetic

562

563

564

565

566

567

568 reconstruction using complete genomic sequences of 17 representative Exiguobacterium strains. The tree was built with PhyloPhlAn (Segata et al., 2013). B) Synteny among Exiguobacterium strains. Nucleotide syntenic blocks are represented by colored bars. Red links denote no rearrangements between the blocks compared. Blue links denote rearrangements between the blocks compared. Blue numbers in the phylogeny denote the minimum number of rearrangements obtained with $M G R$. Plasmids from E. sibiricum are displayed at the right (separated from the chromosome by backslashes). Black numbers indicate bootstrap values different from 100\%.

Figure 2. Differential interference contrast image of $E$. chiriqhucha str. N139.

Figure 3. Circular genome map of . chiriqhucha str. N139. Circle tracks from out towards inside are as follows: 1) Length in nucleotides for each contig; 2) Coding Sequences (CDS) in the Forward Strand (light blue); 3) CDS in the reverse strand (dark blue); 4) Strain Specific Genes (SSGs) in the forward strand (light purple); 5) SSGs in the reverse strand (dark purple); 6) GC Skew (gray). Skew and gene distribution follow that of a typical Firmicute genome. The Strain Specific Genes in the contigs that belong to the chromosome appear to be randomly distributed, whilst they seem to be concentrated in the contigs 12 and 13, which are probably the ones belonging to megaplasmids. The circular plot was done with Circos software (Krzywinski et al., 2009).

Figure 4. Effect of ultraviolet B (UV-B) radiation on Exiguobacterium strains. Percentage survival to UV-B radiation of str. N139 (dark circle), str. S17 (light circle) and str. DSMZ 6208 (dark triangle). The influence of UV-B radiation was studied by exposing liquid cultures to increasing doses, varying exposure times between 0 and 240 minutes. 


\section{References}

Albarracín VH., Dib JR., Ordoñez OF., Farías ME. 2011. A Harsh Life To Indigenous Proteobacteria At the Andean Mountains: Microbial Diversity and Resistance. In: Sezenna ML ed. Proteobacteria: Phylogeny, Metabolic Diversity and Ecological Effects.

Amir-Heidari B., Thirlway J., Micklefield J. 2008. Auxotrophic-precursor directed biosynthesis of nonribosomal lipopeptides with modified tryptophan residues. Organic \& biomolecular chemistry 6:975-978. DOI: 10.1039/b718766c.

Antônio RV., Creczynski-Pasa TB. 2004. Genetic analysis of violacein biosynthesis by Chromobacterium violaceum. Genetics and Molecular Research 3:85-91.

Barkay T., Miller SM., Summers AO. 2003. Bacterial mercury resistance from atoms to ecosystems. FEMS Microbiology Reviews 27:355-384. DOI: 10.1016/S01686445(03)00046-9.

Belfiore C., Ordoñez OF., Farías ME. 2013. Proteomic approach of adaptive response to arsenic stress in Exiguobacterium sp. S17, an extremophile strain isolated from a high-altitude Andean Lake stromatolite. Extremophiles : life under extreme conditions 17:421-31. DOI: 10.1007/s00792-013-0523-y.

Blencke H-M., Homuth G., Ludwig H., Mäder U., Hecker M., Stülke J. 2003. Transcriptional profiling of gene expression in response to glucose in Bacillus subtilis: regulation of the central metabolic pathways. Metabolic Engineering 5:133-149. DOI: 10.1016/S10967176(03)00009-0.

Blencke H-M., Reif I., Commichau FM., Detsch C., Wacker I., Ludwig H., Stülke J. 2006. Regulation of citB expression in Bacillus subtilis: integration of multiple metabolic signals in the citrate pool and by the general nitrogen regulatory system. Arch Microbiol 185:136146. DOI: $10.1007 / \mathrm{s} 00203-005-0078-0$.

Bourque G., Pevzner P a. 2002. Genome-scale evolution: Reconstructing gene orders in the ancestral species. Genome Research 12:26-36.

Burge SW., Daub J., Eberhardt R., Tate J., Barquist L., Nawrocki EP., Eddy SR., Gardner PP., Bateman A. 2013. Rfam 11.0: 10 years of RNA families. Nucleic acids research 41:D22632. DOI: $10.1093 /$ nar/gks 1005 .

Burne R a., Marquis RE. 2000. Alkali production by oral bacteria and protection against dental caries. FEMS Microbiology Letters 193:1-6. DOI: 10.1111/j.1574-6968.2000.tb09393.x. 
617 Cabrol N., McKay C., Grin E., Kiss K., Acs E., Toth B., Grigorszky I., Szabo K., Fike D., Hock 618 A., Demergasso C., Escudero L., Galleguillos P., Chong G., Grigsby B., Zambrana Roman J., Tambley C. 2007. Signatures of habitats and life in Earth's high-altitude lakes: Clues to Noachian aqueous environments on Mars. In: Chapman M ed. The geology of Mars: Evidence from Earth-based analogs. Cambridge: Cambridge University Press, 349-370.

Carneiro AR., Ramos RTJ., Dall'Agnol H., Pinto AC., Soares SDC., Santos AR., Guimarães LC., Almeida SS., Baraúna RA., das Graças DA., Franco LC., Ali A., Hassan SS., Nunes CIP., Barbosa MS., Fiaux KK., Aburjaile FF., Barbosa EGV., Bakhtiar SM., Vilela D., Nóbrega F., dos Santos AL., Carepo MSP., Azevedo V., Schneider MPC., Pellizari VH., Silva A., de Castro Soares S., Santos AR., Guimarães LC., Almeida SS., Baraúna RA., das Graças DA., Franco LC., Ali A., Hassan SS., Nunes CIP., Barbosa MS., Fiaux KK., Aburjaile FF., Barbosa EGV., Bakhtiar SM., Vilela D., Nóbrega F., dos Santos AL., Carepo MSP., Azevedo V., Schneider MPC., Pellizari VH., Silva A. 2012. Genome sequence of Exiguobacterium antarcticum B7, isolated from a biofilm in Ginger Lake, King George Island, Antarctica. Journal of Bacteriology 194:6689-90. DOI: 10.1128/JB.01791-12.

Caspi R., Altman T., Billington R., Dreher K., Foerster H., Fulcher C a., Holland T a., Keseler IM., Kothari A., Kubo A., Krummenacker M., Latendresse M., Mueller L a., Ong Q., Paley S., Subhraveti P., Weaver DS., Weerasinghe D., Zhang P., Karp PD. 2014. The MetaCyc database of metabolic pathways and enzymes and the BioCyc collection of Pathway/Genome Databases. Nucleic Acids Research 42:459-471. DOI: 10.1093/nar/gkt1103.

Chevreux B., Pfisterer T., Drescher B., Driesel AJ., Müller WEG., Wetter T., Suhai S. 2004. Using the miraEST assembler for reliable and automated mRNA transcript assembly and SNP detection in sequenced ESTs. Genome Research 14:1147-1159. DOI: 10.1101/gr.1917404.

Consortium TU. 2015. UniProt : a hub for protein information. 43:204-212. DOI: 10.1093/nar/gku989.

Crapart S., Fardeau ML., Cayol JL., Thomas P., Sery C., Ollivier B., Combet-Blanc Y. 2007. Exiguobacterium profundum sp. nov., a moderately thermophilic, lactic acid-producing bacterium isolated from a deep-sea hydrothermal vent. International Journal of Systematic and Evolutionary Microbiology 57:287-292. DOI: 10.1099/ijs.0.64639-0.

Darling AC., Mau B., Blattner FR., Perna NT. 2004. Mauve: multiple alignment of conserved genomic sequence with rearrangements. Genome Res 14:1394-1403.

Dib J., Motok J., Fernández-Zenoff V., Ordoñez O., Farías ME. 2008. Occurrence of resistance to antibiotics, UV-B, and arsenic in bacteria isolated from extreme environments in highaltitude (above $4400 \mathrm{~m}$ ) Andean wetlands. Current microbiology 56:510-7. DOI: 10.1007/s00284-008-9103-2.

Edgar RC. 2004. MUSCLE: a multiple sequence alignment method with reduced time and space complexity. BMC bioinformatics 5:113. DOI: 10.1186/1471-2105-5-113.

Ericksen GE., Salas RA. 1987. Geology and Resources of Salars in the Central Andes. U.S. 
Geological Survey.

Farías ME., Fernández-Zenoff V., Flores R., Ordóñez O., Estévez C. 2009. Impact of solar radiation on bacterioplankton in laguna vilama, a hypersaline andean lake $(4650 \mathrm{~m})$. Journal of Geophysical Research: Biogeosciences 114:1-8. DOI: 10.1029/2008JG000784.

Farrow JM., Pesci EC. 2007. Two distinct pathways supply anthranilate as a precursor of the Pseudomonas quinolone signal. Journal of Bacteriology 189:3425-3433. DOI: 10.1128/JB.00209-07.

Fernández-Zenoff V., Heredia J., Ferrero M., Siñeriz F., Farías ME. 2006. Diverse UV-B resistance of culturable bacterial community from high-altitude wetland water. Current microbiology 52:359-62. DOI: 10.1007/s00284-005-0241-5.

Fernández-Zenoff V., Siñeriz F., Farías ME. 2006. Diverse responses to UV-B radiation and repair mechanisms of bacteria isolated from high-altitude aquatic environments. Applied and environmental microbiology 72:7857-63. DOI: 10.1128/AEM.01333-06.

Fischer S., Brunk BP., Chen F., Gao X., Harb OS., Iodice JB., Shanmugam D., Roos DS., Stoeckert CJ. 2011. Using OrthoMCL to Assign Proteins to OrthoMCL-DB Groups or to Cluster Proteomes Into New Ortholog Groups. Current protocols in bioinformatics Chapter 6:Unit6.12.

Flores MR., Ordoñez OF., Maldonado MJ., Farías ME. 2009. Isolation of UV-B resistant bacteria from two high altitude Andean lakes $(4,400 \mathrm{~m})$ with saline and non saline conditions. J. Gen. Appl. Microbiol. 55:447-458.

Ge SM., Xie BE., Chen SF. 2006. Characterization of two trpE genes encoding anthranilate synthase ??-subunit in Azospirillum brasilense. Biochemical and Biophysical Research Communications 341:494-499. DOI: 10.1016/j.bbrc.2006.01.009.

Gene Ontology Evidence Codes. Available at http://geneontology.org/page/guide-go-evidencecodes

Gibbons NE., Murray RGE. 1978. Proposals Concerning the Higher Taxa of Bacteria. International Journal of Systematic Bacteriology 28:1-6. DOI: 10.1099/00207713-28-1-1.

Goosen N., Moolenaar GF. 2008. Repair of UV damage in bacteria. DNA Repair 7:353-379. DOI: 10.1016/j.dnarep.2007.09.002.

Goris J., Konstantinidis KT., Klappenbach J a., Coenye T., Vandamme P., Tiedje JM. 2007. DNA-DNA hybridization values and their relationship to whole-genome sequence similarities. International Journal of Systematic and Evolutionary Microbiology 57:81-91. DOI: 10.1099/ijs.0.64483-0.

Gorriti MF., Dias GM., Chimetto LA., Trindade-silva AE., Silva BS., Mesquita MMA., Gregoracci GB., Farias ME., Thompson CC., Thompson FL. 2014. Genomic and phenotypic attributes of novel Salinivibrios from stromatolites, sediment and water from a high altitude lake. BMC Genomics 15:473. 
Gutiérrez-Preciado A., Henkin TM., Grundy FJ., Yanofsky C., Merino E. 2009. Biochemical features and functional implications of the RNA-based T-box regulatory mechanism. Microbiology and molecular biology reviews MMBR 73:36-61. DOI: 10.1128/MMBR.00026-08.

Gutierrez-Preciado A., Jensen R a., Yanofsky C., Merino E. 2005. New insights into regulation of the tryptophan biosynthetic operon in Gram-positive bacteria. Trends in Genetics 21:432-6. DOI: 10.1016/j.tig.2005.06.001.

Gutiérrez-Preciado A., Merino E. 2012. Elucidating metabolic pathways and digging for genes of unknown function in microbial communities: the riboswitch approach. Clinical microbiology and infection: the official publication of the European Society of Clinical Microbiology and Infectious Diseases 18 Suppl 4:35-9. DOI: 10.1111/j.14690691.2012.03864.x.

Gutiérrez-Preciado A., Torres AG., Merino E., Bonomi HR., Goldbaum FA., García-Angulo VA. 2015. Extensive Identification of Bacterial Riboflavin Transporters and Their Distribution across Bacterial Species. Plos One 10:e0126124. DOI: 10.1371/journal.pone.0126124.

Gutiérrez-Preciado A., Yanofsky C., Merino E. 2007. Comparison of tryptophan biosynthetic operon regulation in different Gram-positive bacterial species. Trends in Genetics 23:422426. DOI: $10.1016 /$ j.tig.2007.05.005.

Guy L., Kultima JR., Andersson SGE. 2010. genoPlotR: Comparative gene and genome visualization in R. Bioinformatics 26:2334-2335. DOI: 10.1093/bioinformatics/btq413.

vanden Hoven RN., Santini JM. 2004. Arsenite oxidation by the heterotroph Hydrogenophaga sp. str. NT-14: the arsenite oxidase and its physiological electron acceptor. Biochimica et biophysica acta 1656:148-55. DOI: 10.1016/j.bbabio.2004.03.001.

Jakubauskas A., Kriukiene E., Trinkunaite L., Sapranauskas R., Jurenaite-Urbanaviciene S., Lubys A. 2009. Bioinformatic and partial functional analysis of $\mathrm{pEspA}$ and $\mathrm{pEspB}$, two plasmids from Exiguobacterium arabatum sp. nov. RFL1109. Plasmid 61:52-64. DOI: 10.1016/j.plasmid.2008.09.004.

Jiang X., Xue Y., Wang L., Yu B., Ma Y. 2013. Genome Sequence of a Novel Polymer-Grade L -Lactate-Producing Alkaliphile, Exiguobacterium sp. Strain 8-11-1. Genome Announcements 1:4-5. DOI: 10.1016/j.biortech.

Karami K., Zolgharnei H., Assadi MM., Savari a., Dadollahi S. 2011. New Report on the Occurrence of Exiguobacterium sp. AT1b in the Persian Gulf and its Resistance to Mercury Pollution. Current Research in Bacteriology 4:23-27. DOI: 10.3923/crb.2011.23.27.

Karp PD., Paley SM., Krummenacker M., Latendresse M., Dale JM., Lee TJ., Kaipa P., Gilham F., Spaulding A., Popescu L., Altman T., Paulsen I., Keseler IM., Caspi R. 2009. Pathway Tools version 13.0: Integrated software for pathway/genome informatics and systems biology. Briefings in Bioinformatics 11:40-79. DOI: 10.1093/bib/bbp043.

Kim IG., Lee MH., Jung SY., Song JJ., Oh TK., Yoon JH. 2005. Exiguobacterium aestuarii sp. 
nov. and Exiguobacterium marinum sp. nov., isolated from a tidal flat of the Yellow Sea in Korea. International Journal of Systematic and Evolutionary Microbiology 55:885-889. DOI: $10.1099 / \mathrm{ijs} .0 .63308-0$.

Krzywinski M., Schein J., Birol I., Connors J., Gascoyne R., Horsman D., Jones SJ., Marra MA. 2009. Circos: an information aesthetic for comparative genomics. Genome Res 19:16391645.

Li L., Jr CJS., Roos DS. 2003. OrthoMCL: Identification of Ortholog Groups for Eukaryotic Genomes. Genome Research 13:2178-2189. DOI: 10.1101/gr.1224503.candidates.

López-Cortés A., Schumann P., Pukall R., Stackebrandt E. 2006. Exiguobacterium mexicanum sp. nov. and Exiguobacterium artemiae sp. nov., isolated from the brine shrimp Artemia franciscana. Systematic and Applied Microbiology 29:183-190. DOI: 10.1016/j.syapm.2005.09.007.

López M a., Zavala-Díaz de la Serna FJ., Jan-Roblero J., Romero JM., Hernández-Rodríguez C. 2006. Phylogenetic analysis of a biofilm bacterial population in a water pipeline in the Gulf of Mexico. FEMS microbiology ecology 58:145-54. DOI: 10.1111/j.15746941.2006.00137.x.

Merino E., Jensen R a., Yanofsky C. 2008. Evolution of bacterial trp operons and their regulation. Current Opinion in Microbiology 11:78-86. DOI: 10.1016/j.mib.2008.02.005.

Minko I., Hattman S., Lloyd RS., Kossykh V. 2001. Methylation by a mutant T2 DNA [N(6)adenine] methyltransferase expands the usage of RecA-assisted endonuclease (RARE) cleavage. Nucleic acids research 29:1484-1490.

Mistry J., Finn RD., Eddy SR., Bateman A., Punta M. 2013. Challenges in homology search: HMMER3 and convergent evolution of coiled-coil regions. Nucleic Acids Research 41. DOI: $10.1093 /$ nar/gkt263.

Miteva VI., Sheridan PP., Brenchley JE. 2004. Phylogenetic and Physiological Diversity of Microorganisms Isolated from a Deep Greenland Glacier Ice Core. Appl Environ Microbiol 70:202-213. DOI: 10.1128/AEM.70.1.202.

Nawrocki EP., Eddy SR. 2013. Infernal 1.1: 100-fold faster RNA homology searches. Bioinformatics 29:2933-2935. DOI: 10.1093/bioinformatics/btt509.

Nies DH. 2003. Efflux-mediated heavy metal resistance in prokaryotes. FEMS Microbiology Reviews 27:313-339. DOI: 10.1016/S0168-6445(03)00048-2.

Ordoñez OF., Flores MR., Dib JR., Paz A., Farías ME. 2009. Extremophile culture collection from Andean lakes: extreme pristine environments that host a wide diversity of microorganisms with tolerance to UV radiation. Microbial Ecology 58:461-473. DOI: 10.1007/s00248-009-9527-7.

Ordoñez OF., Lanzarotti E., Kurth D., Gorriti MF., Revale S., Cortez N., Vazquez MP., Farias ME., Turjanski AG., Farías ME., Turjanski AG. 2013. Draft Genome Sequence of the Polyextremophilic Exiguobacterium sp . Strain S17, Isolated from Hyperarsenic Lakes in 
the Argentinian Puna. Genome Announcements 1:e0480-13. DOI: 10.1186/1471-2164-975.Rodrigues.

Orell A., Navarro C a., Arancibia R., Mobarec JC., Jerez C a. 2010. Life in blue: copper resistance mechanisms of bacteria and archaea used in industrial biomining of minerals. Biotechnology advances 28:839-48. DOI: 10.1016/j.biotechadv.2010.07.003.

Oremland RS., Stolz JF. 2003. The ecology of arsenic. Science (New York, N.Y.) 300:939-44. DOI: $10.1126 /$ science. 1081903.

Páez-Espino D., Tamames J., de Lorenzo V., Cánovas D. 2009. Microbial responses to environmental arsenic. Biometals : an international journal on the role of metal ions in biology, biochemistry, and medicine 22:117-30. DOI: 10.1007/s10534-008-9195-y.

Quevillon E., Silventoinen V., Pillai S., Harte N., Mulder N., Apweiler R., Lopez R. 2005. InterProScan: Protein domains identifier. Nucleic Acids Research 33:116-120. DOI: 10.1093/nar/gki442.

Ramphall R., Pier GB. 1985. Role of Pseudomonas aeruginosa Mucoid Exopolysaccharide in Adherence to Tracheal Cells. Infection and Immunity 47:1-4.

Rebollar E a., Avitia M., Eguiarte LE., González-González A., Mora L., Bonilla-Rosso G., Souza V. 2012. Water-sediment niche differentiation in ancient marine lineages of Exiguobacterium endemic to the Cuatro Cienegas Basin. Environmental Microbiology 14:2323-33. DOI: 10.1111/j.1462-2920.2012.02784.x.

Rissman AI., Mau B., Biehl BS., Darling AE., Glasner JD., Perna NT. 2009. Reordering contigs of draft genomes using the Mauve Aligner. Bioinformatics 25:2071-2073. DOI: 10.1093/bioinformatics/btp356.

Rodrigues DF., Ivanova N., He Z., Huebner M., Zhou J., Tiedje JM. 2008. Architecture of thermal adaptation in an Exiguobacterium sibiricum strain isolated from 3 million year old permafrost: a genome and transcriptome approach. BMC genomics 9:547. DOI: 10.1186/1471-2164-9-547.

Rollins SM. 2002. The mRNA/tRNA interaction promoting $\mathrm{T}$ box transcriptional antitermination. The Ohio State University, Columbus, $\mathrm{OH}$.

Rosen BP. 1999. Families of arsenic transporters. Trends in microbiology 7:207-12.

Rout SP., Rai A., Humphreys PN. 2015. Draft Genome Sequence of Alkaliphilic Exiguobacterium sp . Strain HUD, Isolated from a Polymicrobial Consortia. Genome Announcements 3:9-10. DOI: 10.1128/genomeA.01451-14.Copyright.

Sacheti P., Bhonsle H., Patil R., Kulkarni MJ., Srikanth R., Gade W. 2013. Arsenomics of Exiguobacterium sp. PS (NCIM 5463). RSC Advances 3:9705. DOI: 10.1039/c3ra40897c.

Seemann T. 2014. Prokka: Rapid prokaryotic genome annotation. Bioinformatics 30:2068-2069. DOI: 10.1093/bioinformatics/btu153. 
806

Segata N., Börnigen D., Morgan XC., Huttenhower C. 2013. PhyloPhlAn is a new method for improved phylogenetic and taxonomic placement of microbes. Nature communications 4:2304. DOI: $10.1038 /$ ncomms3304.

Silver S., Phung LT. 2005. A bacterial view of the periodic table: genes and proteins for toxic inorganic ions. Journal of industrial microbiology \& biotechnology 32:587-605. DOI: 10.1007/s10295-005-0019-6.

Sommer S., Bailone A., Universitaire C. 1998. Specific RecA amino acid changes affect RecA UmuDJC interaction. Molecular Microbiology 28:281-291.

Ventosa A., Nieto JJ., Oren A. 1998. Biology of Moderately Halophilic Aerobic Bacteria. Microbiology and Molecular Biology Reviews 62:504-544.

Vishnivetskaya TA., Chauhan A., Layton AC., Pfiffner SM., Huntemann M., Copeland A., Chen A., Kyrpides NC., Markowitz VM., Palaniappan K., Ivanova N., Mikhailova N., Ovchinnikova G., Andersen EW., Pati A., Stamatis D., Reddy TBK., Shapiro N., Nordberg HP., Cantor MN., Hua XS. 2014. Draft Genome Sequences of 10 Strains of the Genus Exiguobacterium. 2:10-11. DOI: 10.1128/genomeA.01058-14.Copyright.

Vishnivetskaya T a., Kathariou S. 2005. Putative transposases conserved in Exiguobacterium isolates from ancient Siberian permafrost and from contemporary surface habitats. Applied and Environmental Microbiology 71:6954-6962. DOI: 10.1128/AEM.71.11.69546962.2005 .

Vishnivetskaya T a., Kathariou S., Tiedje JM. 2009. The Exiguobacterium genus: biodiversity and biogeography. Extremophiles 13:541-55. DOI: 10.1007/s00792-009-0243-5.

Vishnivetskaya T a., Lucas S., Copeland A., Lapidus A., del Rio TG., Dalin E., Tice H., Bruce DC., Goodwin L a., Pitluck S., Saunders E., Brettin T., Detter C., Han C., Larimer F., Land ML., Hauser LJ., Kyrpides NC., Ovchinnikova G., Kathariou S., Ramaley RF., Rodrigues DF., Hendrix C., Richardson P., Tiedje JM. 2011. Complete genome sequence of the thermophilic bacterium Exiguobacterium sp. AT1b. Journal of Bacteriology 193:28802881. DOI: 10.1128/JB.00303-11.

Vishnivetskaya T a., Petrova M a., Urbance J., Ponder M., Moyer CL., Gilichinsky D a., Tiedje JM. 2006. Bacterial community in ancient Siberian permafrost as characterized by culture and culture-independent methods. Astrobiology 6:400-414. DOI: 10.1089/ast.2006.6.400.

De Vos P., Garrity GM., Jones D., Krieg NR., Ludwig W., Rainey FA., Schleifer KH., Whitman WB. (eds.) 2009. Bergey's Manual of Systematic Bacteriology. New York: Springer.

White III RA., Grassa CJ., Suttle CA. 2013. Draft genome sequence of Exiguobacterium pavilionensis Strain RW-2, with Wide Thermal, Salinity, and $\mathrm{pH}$ Tolerance, Isolated from Modern Freshwater Microbioalites. Genome announcements 1:e0057-13. DOI: doi:10.1128/genomeA.00597-13.

Woese CR., Kandler O., Wheelis ML. 1990. Towards a natural system of organisms: proposal for the domains Archaea, Bacteria, and Eucarya. Proceedings of the National Academy of 
$844 \quad$ Sciences of the United States of America 87:4576-4579. DOI: 10.1073/pnas.87.12.4576.

845 Yuan M., Chen M., Zhang W., Lu W., Wang J., Yang M., Zhao P., Tang R., Li X., Hao Y., Zhou 846 Z., Zhan Y., Yu H., Teng C., Yan Y., Ping S., Wang Y., Lin M. 2012. Genome sequence 847 and transcriptome analysis of the radioresistant bacterium deinococcus gobiensis: Insights 848 into the extreme environmental adaptations. PLOS ONE 7:1-11. DOI:

$849 \quad$ 10.1371/journal.pone.0034458.

850 


\section{Figure 1 (on next page)}

Evolutionary history of the genus Exiguobacterium

Evolutionary history of the genus Exiguobacterium . A) Phylogenetic reconstruction using complete genomic sequences of 17 representative Exiguobacterium strains. The tree was built with PhyloPhIAn (Segata et al., 2013) . B) Synteny among Exiguobacterium strains. Nucleotide syntenic blocks are represented by colored bars. Red links denote no rearrangements between the blocks compared. Blue links denote rearrangements between the blocks compared. Blue numbers in the phylogeny denote the minimum number of rearrangements obtained with MGR. Plasmids from E. sibiricum are displayed at the right (separated from the chromosome by backslashes). Black numbers indicate bootstrap values different from $100 \%$. 
A

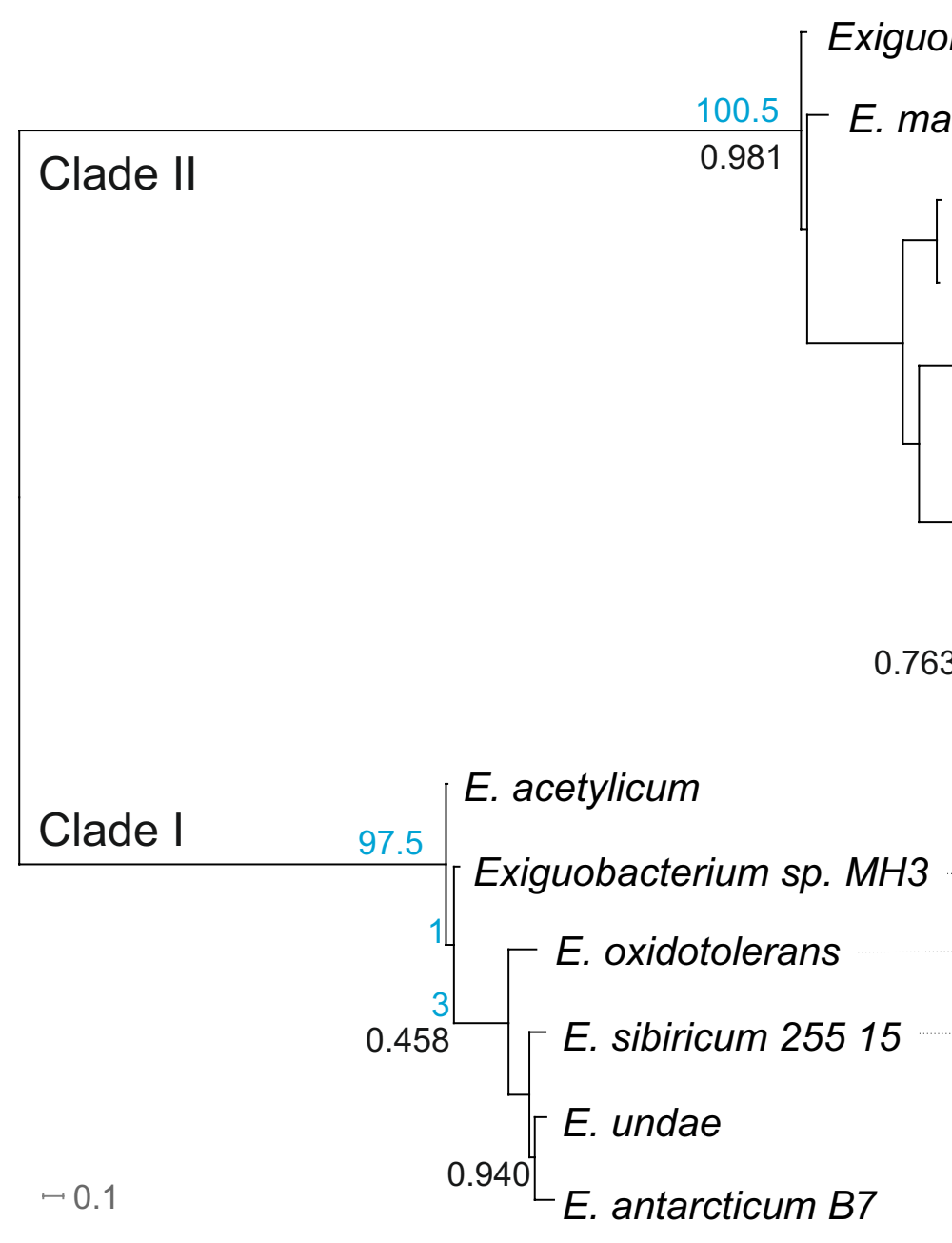

B
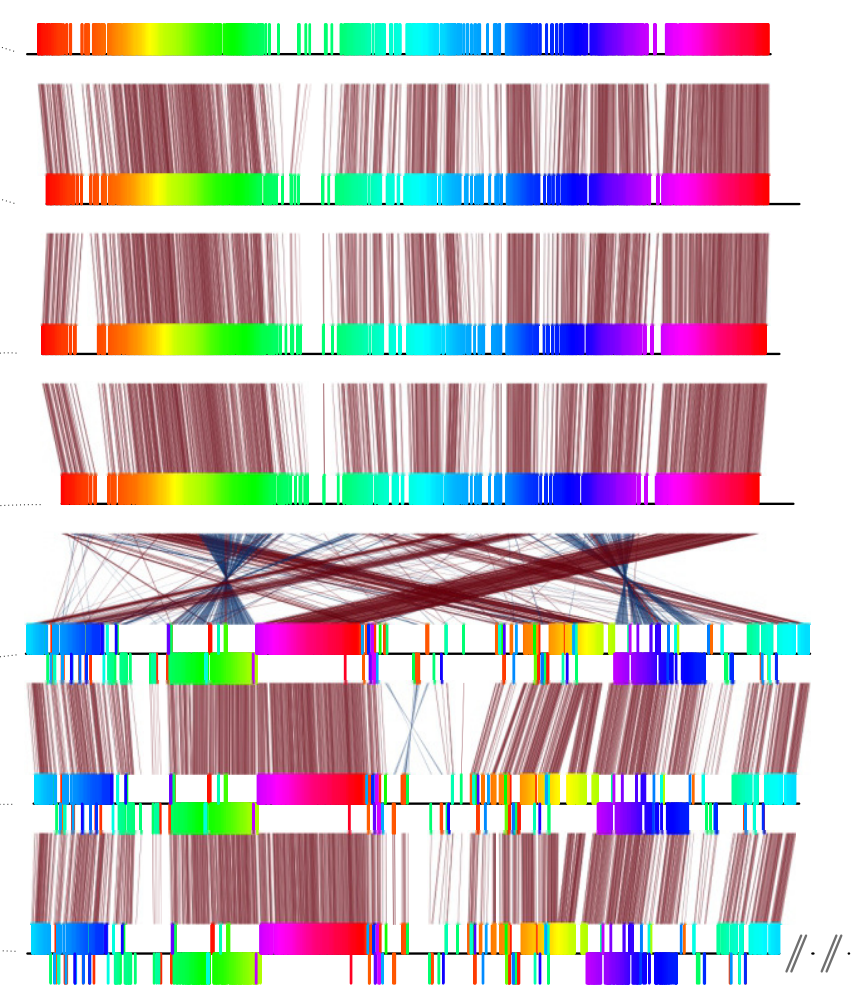

$500 \mathrm{~kb}$ 


\section{Figure 2}

Differential interference contrast image of E. pavilionensis str. N139

*Note: Auto Gamma Correction was used for the image. This only affects the reviewing manuscript. See original source image if needed for review.

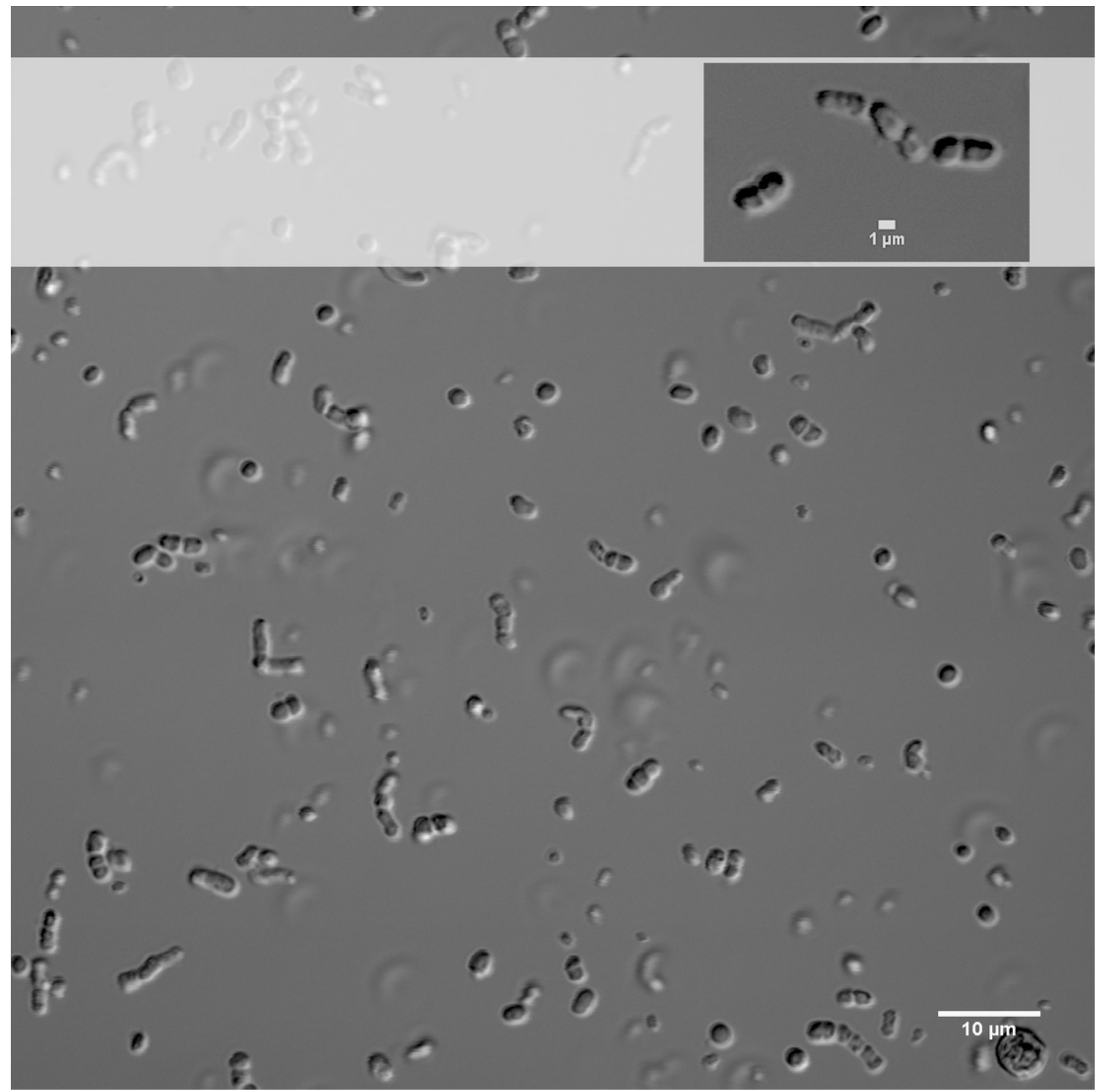




\section{Figure 3 (on next page)}

Circular genome map of E. pavilionensis str. N139

Circle tracks from out towards inside are as follows: 1) Length in nucleotides for each contig;

2) Coding Sequences (CDS) in the Forward Strand (light blue); 3) CDS in the reverse strand (dark blue); 4) Strain Specific Genes (SSGs) in the forward strand (light purple); 5) SSGs in the reverse strand (dark purple); 6) GC Skew (gray). Skew and gene distribution follow that of a typical Firmicute genome. The Strain Specific Genes in the contigs that belong to the chromosome appear to be randomly distributed, whilst they seem to be concentrated in the contigs 12 and 13, which are probably the ones belonging to megaplasmids. The circular plot was done with Circos software (Krzywinski et al., 2009). 


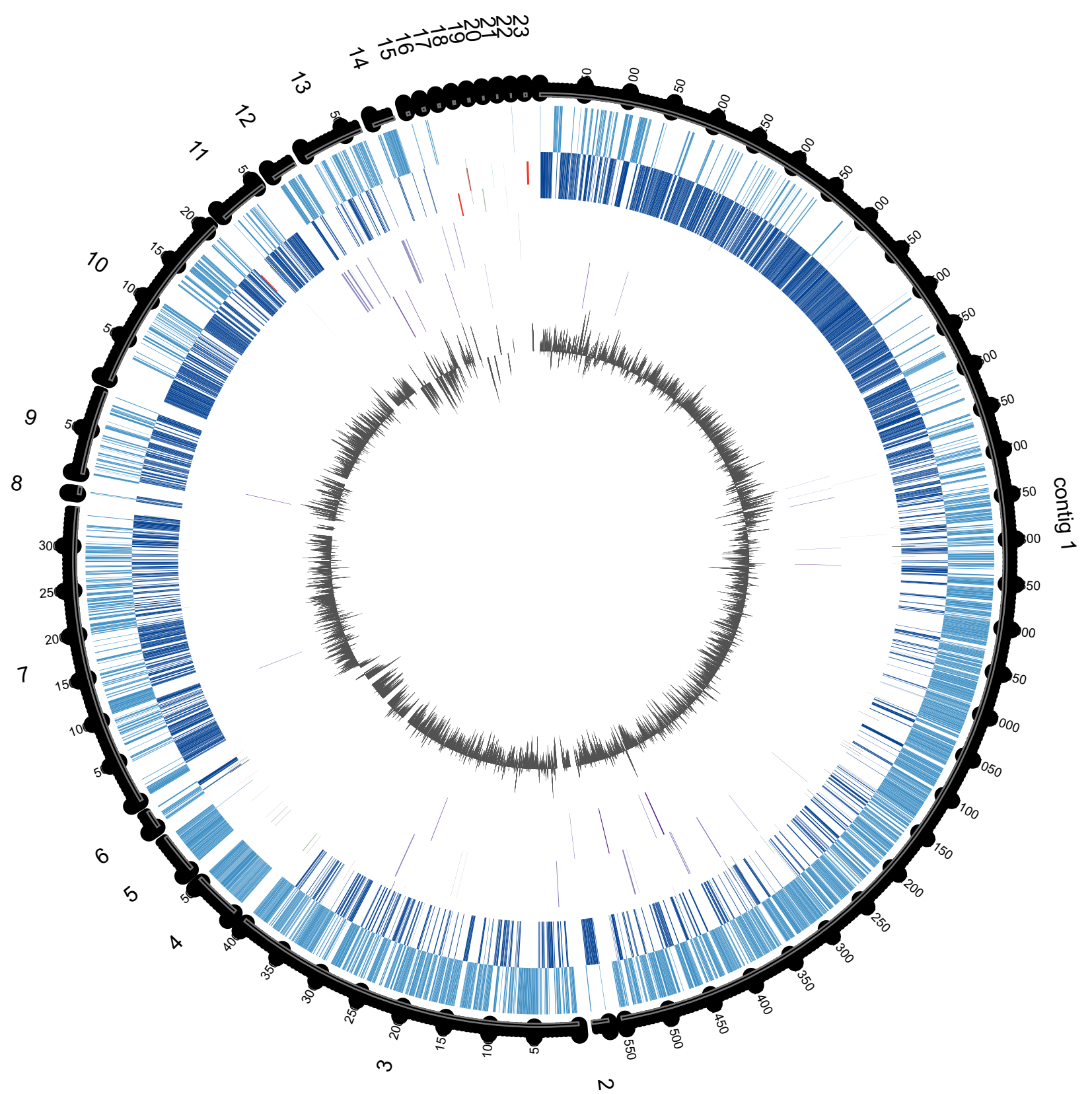




\section{Figure 4}

Effect of ultraviolet B (UV-B) radiation on Exiguobacterium strains

Percentage survival to UV-B radiation of str. N139 (dark circle), str. S17 (light circle) and str. DSMZ 6208 (dark triangle). The influence of UV-B radiation was studied by exposing liquid cultures to increasing doses, varying exposure times between 0 and 240 minutes. 


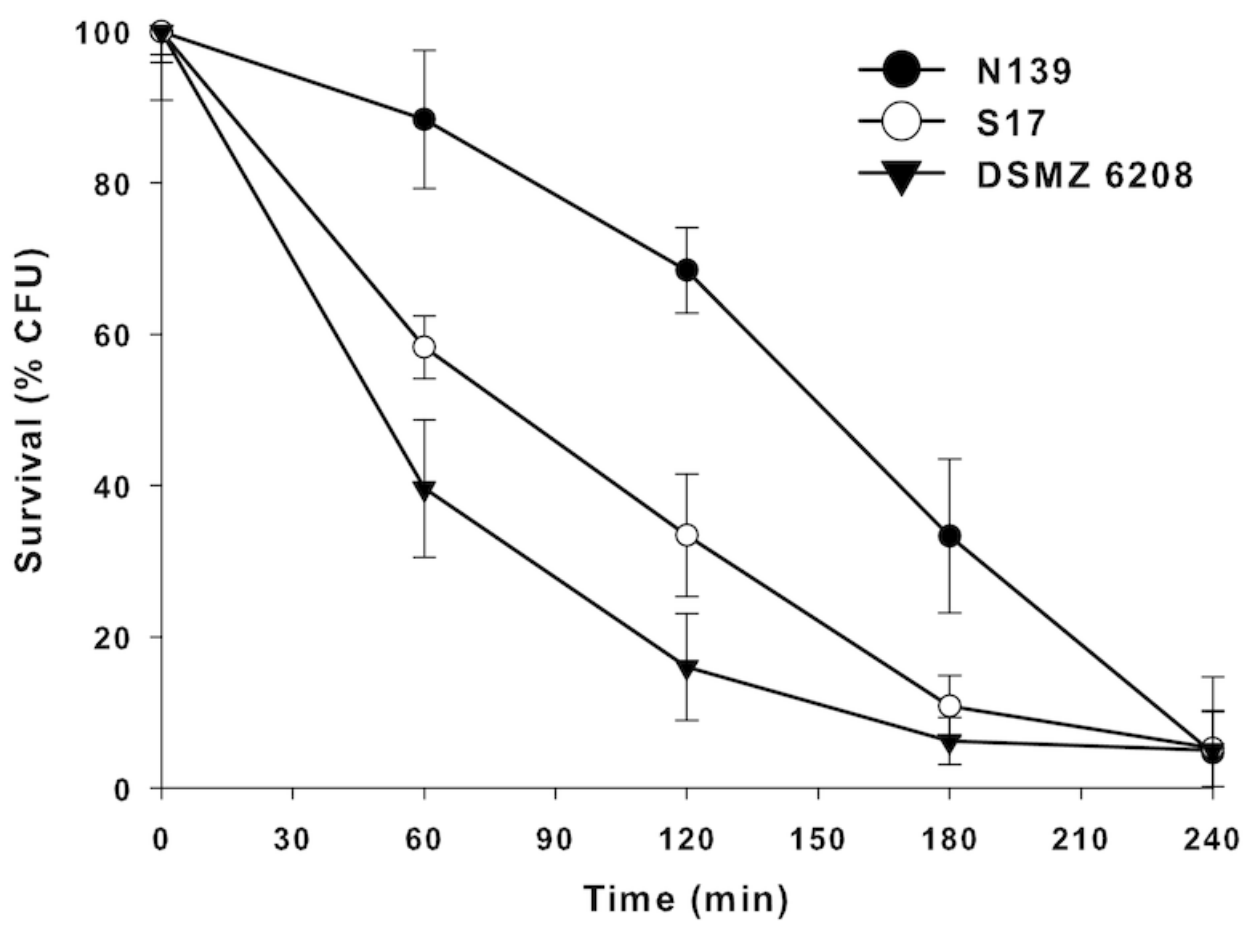




\section{Table $\mathbf{1}$ (on next page)}

Classification and general features of Exiguobacterium pavilionensis str. N139

a Evidence codes - IDA: Inferred from Direct Assay; TAS: Traceable Author Statement (i.e., a direct report exists in the literature); NAS: Non-traceable Author Statement (i.e., not directly observed for the living, isolated sample, but based on a generally accepted property for the species, or anecdotal evidence); EXP: Inferred from Experiment. These evidence codes are from the Gene Ontology project ("Gene Ontology Evidence Codes") 
1 Table 1. Classification and general features of Exiguobacterium chiriqhucha str. N139

\begin{tabular}{|c|c|c|}
\hline Property & Term & Evidence code $^{\mathbf{a}}$ \\
\hline \multirow[t]{8}{*}{ Classification } & Domain Bacteria & TAS (Woese, Kandler \& Wheelis, 1990) \\
\hline & Phylum Firmicutes & TAS (Gibbons \& Murray, 1978) \\
\hline & Class Bacilli & TAS (De Vos et al., 2009) \\
\hline & Order Bacillales & TAS (De Vos et al., 2009) \\
\hline & Family Bacillales Family XII. Incertae Sedis & TAS (De Vos et al., 2009) \\
\hline & Genus Exiguobacterium & $\begin{array}{l}\text { TAS (De Vos et al., 2009; } \\
\text { Vishnivetskaya, Kathariou \& Tiedje, } \\
\text { 2009) }\end{array}$ \\
\hline & Species Exiguobacterium chiriqhucha & TAS (White III, Grassa \& Suttle, 2013) \\
\hline & Strain: N139 (Accession: JMEH00000000) & \\
\hline Gram stain & Positive & IDA \\
\hline Cell shape & Short rods & IDA \\
\hline Motility & Motile & IDA \\
\hline Sporulation & Non-sporulating & EXP \\
\hline Temperature range & Mesophilic $\left(30-37^{\circ} \mathrm{C}\right)$ & IDA \\
\hline Optimum temperature & $30^{\circ} \mathrm{C}$ & IDA \\
\hline pH range; Optimum & $7-9$ & IDA \\
\hline Carbon source & $\begin{array}{l}\text {-Methylglucoside, Galacturonic acid, } L- \\
\text { asparagine, Tween 40, L-Serine, N-acetyl- } \\
\text { glucosamine, Hydroxybutyric acid, Itaconic } \\
\text { acid, Ketobutyric acid, Putrescine (See table } \\
\text { S1) }\end{array}$ & EXP \\
\hline Habitat & Aquatic & TAS (Flores et al., 2009) \\
\hline Salinity & $0.11 \%-10 \% \mathrm{NaCl}(w / v)$ & IDA \\
\hline Oxygen requirement & Facultatively anaerobic & TAS (De Vos et al., 2009) \\
\hline Biotic relationship & free-living & IDA \\
\hline Pathogenicity & non-pathogen & NAS \\
\hline Geographic location & Laguna Negra, Catamarca, Argentina & IDA \\
\hline Sample collection & 2006 & IDA \\
\hline Latitude & $27^{\circ} 39^{\prime} 20.17^{\prime \prime} \mathrm{S}$ & IDA \\
\hline Longitude & $68^{\circ} 33^{\prime} 46.18^{\prime \prime} W$ & IDA \\
\hline Altitude & $4100 \mathrm{masl}$ & IDA \\
\hline
\end{tabular}

${ }^{a}$ Evidence codes - IDA: Inferred from Direct Assay; TAS: Traceable Author Statement (i.e., a direct report exists in the literature); NAS: Non-traceable Author Statement (i.e., not directly observed for the living, isolated sample, but based on a generally accepted property for the species, or anecdotal evidence); EXP: Inferred from Experiment. These evidence codes are from the Gene Ontology project ("Gene Ontology Evidence Codes") 
Table 2 (on next page)

Project information 
1 Table 2. Project information.

\begin{tabular}{ll} 
Property & Term \\
\hline Finishing quality & Permanent-draft \\
Libraries used & 454 pyrosequence standard library \\
Sequencing platforms & 454 Titanium \\
Fold coverage & $85 \mathrm{x}$ \\
Assemblers & Newbler 2.8 and MIRA 3.4 \\
Gene calling method & Prokka \\
Locus Tag & EF88 \\
Genbank ID & JMEH00000000.1 \\
GenBank Date of Release & December, 2015 \\
GOLD ID & Go0093977 \\
BIOPROJECT & PRJNA245187 \\
Source Material Identifier & N139 \\
Project Relevance & UV resistance, metal resistance, adaptation to \\
\hline
\end{tabular}




\section{Table 3(on next page)}

Nucleotide content and gene count levels of the E. pavilionensis str. N139 genome

a) The total is based on either the size of the genome in base pairs or the total number of protein coding genes in the annotated genome. 
1 Table 3. Nucleotide content and gene count levels of the E. chiriqhucha str. N139 genome

\begin{tabular}{lrl}
\hline Attribute & \multicolumn{2}{c}{ Genome (total) } \\
\hline & Value & \multicolumn{1}{c}{$\%$} \\
\hline Genome size (bp) & $2,952,588$ & - \\
\hline DNA coding (bp) & \\
\hline DNA G+C (bp) & $2,655,834$ & 89.94 \\
\hline DNA Scaffolds & 52 \\
\hline Total genes & 23 & \\
\hline RNA genes & 3,182 & 100 \\
\hline Protein-coding genes & 82 & 2.62 \\
\hline Pseudogenes & 3,049 & 95.82 \\
\hline Genes in internal clusters & 26 & 0.81 \\
\hline Genes with function prediction & $\mathrm{NA}$ & \\
\hline Genes assigned to COGs & 2,356 & 74.04 \\
\hline Genes with Pfam domains & 2,575 & 80.92 \\
\hline Genes with signal peptides & 2,538 & 79.76 \\
\hline Genes with transmembran helices & $\mathrm{NA}$ & \\
\hline CRISPR repeats & 888 & 27.90 \\
\hline
\end{tabular}

2 a) The total is based on either the size of the genome in base pairs or the total number of protein 3 coding genes in the annotated genome. 


\section{Table 4 (on next page)}

Genes associated with the 25 general COG functional categories

a) The total is based on the total number of protein coding genes in the annotated genome. 
1 Table 4. Genes associated with the 25 general COG functional categories

\begin{tabular}{cccl}
\hline Code & Value & \% of total & Description \\
\hline J & 166 & 5.44 & Translation, ribosomal structure and biogenesis \\
A & 0 & 0 & RNA processing and modification \\
K & 235 & 7.71 & Transcription \\
L & 144 & 4.72 & Replication, recombination and repair \\
B & 1 & 0.03 & Chromatin structure and dynamics \\
& & & Cell cycle control, Cell division, chromosome \\
D & 36 & 1.18 & partitioning \\
V & 62 & 2.03 & Defense mechanisms \\
T & 166 & 5.44 & Signal transduction mechanisms \\
M & 144 & 4.72 & Cell wall/membrane biogenesis \\
N & 75 & 2.46 & Cell motility \\
U & 53 & 1.74 & Intracellular trafficking and secretion \\
& & & Posttranslational modification, protein turnover, \\
O & 100 & 3.28 & chaperones \\
C & 152 & 4.99 & Energy production and conversion \\
G & 232 & 7.61 & Carbohydrate transport and metabolism \\
E & 224 & 7.35 & Amino acid transport and metabolism \\
F & 84 & 2.76 & Nucleotide transport and metabolism \\
H & 97 & 3.18 & Coenzyme transport and metabolism \\
I & 81 & 2.66 & Lipid transport and metabolism \\
P & 170 & 5.58 & Inorganic ion transport and metabolism \\
& & & Secondary metabolites biosynthesis, transport \\
Q & 54 & 1.77 & and catabolism \\
R & 463 & 15.19 & General function prediction only \\
S & 327 & 10.72 & Function unknown \\
- & 447 & 15.55 & Not in COG \\
\hline
\end{tabular}

2 aThe total is based on the total number of protein coding genes in the annotated genome. 